\title{
APROXIMACIÓN TEÓRICA AL CONCEPTO DE SECURITIZACIÓN DE LA POLÍTICA MIGRATORIA.
}

\author{
THEORETICAL APPROACH TO THE CONCEPT OF SECURITIZATION \\ OF MIGRATION POLICIES.
}

APPROCHE THÉORIQUE DU CONCEPT DE SÉCURISATION DE LA

POLITIQUE MIGRATOIRE.

APROXIMAÇÃO TEÓRICA AO CONCEITO DE SECURITIZAÇÃO DE POLÍTICA DE MIGRAÇÃO.

María Isolda Perelló Carrascosa*

Resumen: La percepción negativa de la migración irregular y la narrativa del miedo, se han visto exacerbadas a partir de la crisis económica mundial de 2008, contribuyendo a que el paradigma de la seguridad nacional sea el imperante en el discurso político actual a escala global, frente al discurso de los derechos humanos. Por consiguiente, la retórica securitizadora ha ido dominando el debate político de una manera tal, que se está dejando en un segundo plano la cuestión de cómo pueden las migraciones contribuir al desarrollo de los países. Como se verá a continuación, el abandono del enfoque humanitario en la política migratoria, conlleva la criminalización de la pobreza y de la migración, debido a la determinación de la figura del extranjero como una potencial amenaza para la estabilidad o el orden público de las naciones. Por ello, el marco interpretativo de la Teoría de la Securitización de la Escuela de Copenhague y los nuevos enfoques de los Estudios Críticos de Seguridad, servirán para comprender cómo la militarización de la política de control de flujos migratorios ha ido adquiriendo una mayor dimensión en el panorama internacional, gracias también a la globalización de los riesgos.

Palabras clave: Securitización, política migratoria, migraciones, amenaza, riesgos. * Doctoranda en el Programa de Doctorado en Ciencias Sociales de la Universidad de Valencia
(UV), Valencia, España; E-mail: isoldapc@gmail.com 
ABSTRACT: The negative perception of irregular migration and fearmongering have been exacerbated since the global financial crisis of 2008, leading the national security paradigm to prevail worldwide in the political discourse of current times, in detriment of the human rights discourse. As a result, the securitization rhetoric has taken hold of political debate to such an extent that it is leaving the issue of how migrations can contribute to the development of countries in the background. As discussed below, the abandonment of the humanitarian focus on migration policy results in the criminalization of poverty and immigration, stemming from the perception of the foreigner as a potential threat to the stability of public order in nations. In light of this, the interpretative framework of the Securitization Theory of the Copenhagen School and the new focuses of the Critical Security Studies will be useful to understand how the militarization of the migration flow control policy has gained a greater importance in the international landscape, also in part due to the globalization of risks.

Keywords: Securitization, migration policy, migration, threat, risks.

$\boldsymbol{R} \boldsymbol{E} \boldsymbol{S U M E}$ : La perception négative de la migration irrégulière et le récit de la peur ont été exacerbés par la crise économique mondiale de 2008, contribuant au paradigme de la sécurité nationale prévalant dans le discours politique actuel à l'échelle global, par opposition au discours sur les droits de l'homme. Par conséquent, la rhétorique de la sécurisation a dominé le débat politique de telle sorte que la question de savoir comment les migrations peuvent contribué au développement des pays est laissée de côté. Comme on le verra ci-dessous, l'abandon de l'approche humanitaire dans la politique migratoire implique la criminalisation de la pauvreté et des migrations, en raison de la détermination du la figure de l'étranger en tant que menace potentielle pour la stabilité ou l'ordre public des nations. Par conséquent, le cadre interprétatif de la théorie de la sécurisation de l'École de Copenhague et les nouvelles approches des études critiques de la sécurité permettront de comprendre comment la militarisation de la politique de contrôle des flux migratoires pris une plus grande dimension dans la scène internationale, grâce également à la mondialisation des risques.

Mots clés: sécurisation, politique migratoire, migration, menace, risques.

Resumo: A percepção negativa da migração irregular e a narrativa do medo, tem sido exacerbada desde a crise económica mundial de 2008, contribuindo para que o paradigma da segurança nacional seja imperativo no discurso político atual a um nível 
global, ultrapassando o discurso dos direitos humanos. Por consequência, a retórica de securitização tem dominado o debate político de maneira que, se deixa para segundo plano a questão de como as migrações podem contribuir para o desenvolvimento dos países. Como poderá ver mais adiante, o abandono no foco humanitário na política migratória, contribui para a criminalização da pobreza e da migração, devido ao estabelecimento da figura estrangeira como uma potencial ameaça para a estabilidade ou ordem pública das nações. Por isso, o quadro interpretativo da Teoria da Securitização da Escola de Copenhague e os novos focos dos Estudos Críticos de Segurança, servirão para compreender como a militarização da política de controlo de fluxos migratórios tem vindo a adquirir uma maior dimensão no panorama internacional, graças também à globalização dos riscos.

Palavras-chave: Securitização, política de migração, migração, ameaça, riscos.

\section{INTRODUCCIÓN: GLOBALIZACIÓN Y GESTIÓN MI- GRATORIA.}

El fenómeno de la globalización financiera, ha instaurado un nuevo orden planetario, en el que la lógica neoliberal-neocolonial ha alterado las relaciones sociales y económicas en relación con el territorio, a causa de la emergencia de poderes de índole económico, institucional o social a nivel global, que transcienden la base territorial de los Estados. Este hecho ha contribuido al desdibujamiento de las fronteras, desafiando este esquema tradicional del Estado nación y cuestionando el papel defensivo de las mismas como su principal baluarte. Esto significa que para el Estado su prioridad ya no será únicamente la preservación del territorio, sino que en aras de garantizar la seguridad frente a las posibles amenazas, se centrará en la regulación de los flujos comerciales entre países y de los "sujetos-objetos que los transitan" (Mendiola, 2012, p. 448; Brown, 2015).

En ese contexto, la libertad de circulación de las personas ha estado (y sigue estando) enormemente restringida por las naciones receptoras, en aras de proteger su soberanía. Así, la selectividad de las migraciones estará condicionada por la posesión de un título jurídico que permita la entrada, el tránsito, la permanencia en el país de des- 
tino, o el acceso al derecho al asilo y refugio (Appadurai, 1996, apud CEPAL, 2006, p. 20; Arango, 2003). Además, la adopción de políticas específicas para regular y frenar la llegada de migrantes, ha hecho que modalidades que en épocas anteriores eran fundamentales, como las migraciones laborales y las que conducen a la residencia permanente, se hayan visto severamente mermadas (Arango, 2007).

El resultado es que el régimen migratorio prevalente tanto en las denominadas "democracias occidentales", como "en las legislaciones contemporáneas de todos los continentes" (Kamto, 2005, p. 211), esté fundamentado en la inclusión de medidas cada vez más restrictivas. Así, junto con el cierre de fronteras, se incorporan prohibiciones legales específicas de entrada, recurriendo con cierta frecuencia a actuaciones coercitivas excepcionales que recaen sobre las personas migrantes no autorizadas, especialmente a través de la vía de las deportaciones masivas. Unas prácticas que eran asociadas en épocas anteriores exclusivamente a regímenes dictatoriales.

Como indica Esteban de la Rosa (2016), por lo general es aceptado que el Estado ejerza el control de sus fronteras nacionales para impedir la llegada de personas, especialmente respecto de aquellas que se hallen en situación irregular y carezcan de la documentación requerida para su entrada, en aras de "salvaguardar la seguridad de todos los ciudadanos que residen en un determinado territorio [...]"'(Esteban de la Rosa, 2016, p. 91). Igualmente, hay que tener en cuenta que el derecho de expulsar a un extranjero de su territorio, es un derecho inherente del Estado que deriva de la soberanía nacional, y que le otorga un margen de discrecionalidad mayor a la hora de poner en marcha este tipo de medidas (CDI, 2014). De ahí que las expulsiones hayan contribuido también a la configuración de un sistema que discrimina entre quienes tienen derecho o no a entrar y a vivir en el territorio de un país, quedando expuesta la racionalidad neoliberal, promotora del intercambio comercial entre países, mientras dificulta el libre movimiento de personas (Kamto, 2005, p. 211). Aunque conviene subrayar que esta soberanía no es absoluta, puesto que tales prerrogativas son sujetas a las obligaciones derivadas de cualquier acuerdo o convenio internacional de protección 
de los Derechos Humanos que haya sido ratificado (CIDH, 17 de septiembre de 2003).

Desprendidas de este patrón restrictivo, se encuentran las políticas migratorias selectivas, cuyo objeto es promover el ingreso y establecimiento de personas que cumplan un determinado perfil, según las necesidades de cada momento (Vargas-Céspedes, 2010, p. 59). Éstas estarán determinadas por la promoción de la entrada y estancia de ciertas categorías de extranjeros a través de medidas administrativas, cuya predisposición a la integración en la sociedad receptora pueda resultar mayor que otras, por razón de aspectos tales como la lengua o la religión (López-Sala, 2005a, p. 33).

Dentro de esta última categoría, se ha ido desarrollando una forma ambigua de intervención, estrechamente vinculada al concepto de la "gobernanza de la migración internacional", y que es denominada por Doménech (2013) como "política migratoria con rostro humano". Según la Oficina del Alto Comisionado para los Derechos Humanos de Naciones Unidas (2015), puede entenderse por gobernanza de la migración internacional:

[...] el proceso en el que el marco conjunto de normas jurídicas y estructuras orgánicas regulan y determinan el actuar de los Estados en respuesta a la migración internacional, al tiempo que se abordan derechos y obligaciones, fomentando para ello la cooperación internacional (OHCHR, 2015, p. 9).

Este término surgió en el I Simposio internacional celebrado en Bangkok en 1999, donde se abordaba la cooperación regional para hacer frente al desafío económico, social, humanitario, político y securitario que representaba el fenómeno de la migración irregular y de las personas indocumentadas, culminando con la Declaración de Bangkok. A través de la misma, lo que se buscaba era alcanzar acuerdos para la aprobación de políticas integrales, coherentes y eficaces, que estuvieran basadas en una estrategia desarrollada a largo plazo dentro de un marco regional amplio. Por tanto, debían ser consideradas las causas, manifestaciones y efectos de las migraciones, tanto positivos como negativos, 
en los países de origen, tránsito y destino (GRFDT, 2 de noviembre de 2016). Como señala Sassen (2003), se produjo entonces una "transnacionalización de facto" en la gestión de los asuntos migratorios, por lo que los Estados ya no se ceñían al ámbito de sus fronteras nacionales, sino que se involucraron también actores sociales y políticos de carácter nacional o transnacional, tanto a nivel local como supranacional.

Dicho modelo que cobró mayor importancia tras los atentados del 11-S, pretende superar el binomio que enfrenta a la seguridad y los derechos humanos, para relacionarlos con el concepto de desarrollo. Su enfoque fue incorporado en el espacio iberoamericano tras la Cumbre de Salamanca de 2005 (Santi 2010, apud Pereira, 4 de mayo de 2014), momento a partir del cual se hacía una clara referencia a la necesidad de respetar los derechos humanos como fundamento de las "buenas prácticas" en las políticas migratorias (Pereira, 4 de mayo de 2014). Igualmente, en 2006 se celebró la I Conferencia Ministerial Euroafricana sobre Migración y Desarrollo, conocida como Proceso de Rabat, cuyo objetivo inmediato fue la consecución de fórmulas que incrementaran los efectos positivos de la migración sobre los países de origen, tránsito y destino (Sorroza, 2006). Señala Kamto (2006, p. 243) que su Plan de Intervención tenía por objetivo frenar la migración irregular, mediante la actuación coordinada y el fortalecimiento del control de fronteras. A tal efecto, se han suscrito acuerdos bilaterales y multilaterales para incidir en las políticas migratorias y facilitar el control de flujos en origen a través de instrumentos como la cooperación al desarrollo (Mármora, 2004, apud Magliano y Clavijo, 2011, p. 154; Ceriani, 2007, p. 4).

De esta forma, se pretendía crear una forma de gestión del fenómeno migratorio alternativa a los postulados propios de la doctrina de seguridad nacional, los cuales, buscan ejercer el control de los desplazamientos a través de políticas restrictivas, con la consiguiente criminalización de las personas migrantes (Mármora, 2004, p. 391, apud Magliano y Clavijo, 2011, p. 154). Martínez y Stang (2005, p. 67) indican que Naciones Unidas advirtió que la ideologización en Estados Unidos y en la Unión Europea de la política antiterrorista que vinculaba la cuestión securitaria con la migración, sirvió para justificar me- 
didas propias de estados de excepción, permitiendo que determinados derechos quedaran suspendidos. Esta circunstancia fue acompañada además de la estigmatización de determinados ciudadanos por razón de su país de origen, así como por motivos raciales y étnicos, con la consiguiente violación de sus derechos humanos.

Así que como afirma Doménech (2013), con la gobernabilidad migratoria, podría lograrse que "la lógica estatocéntrica de la soberanía nacional" no contradijera el "imperativo universalista abstracto" del régimen internacional de los derechos humanos (Doménech, 2013, p. 2). Esto era debido a que desde este enfoque, se cuestionaba el papel del Estado nación y sus "decisiones soberanas" frente al ingreso, aceptación, integración y devolución de migrantes (Martínez y Stang, 2005). Posteriormente, con el estallido de la crisis financiera global de 2008, y tras constatar la imposibilidad de los Estados nación de regular la migración de manera unilateral, se apeló nuevamente a la instauración de un orden que propiciara el control de los movimientos poblacionales de una manera más efectiva (Hansen, 2010; Santi, 2011, apud Doménech, 2013, pp. 4 y 5).

Sin embargo, aunque el fundamento ideológico de tales políticas migratorias esté enmarcado dentro de este discurso humanitario, sus ideas y prácticas han servido en realidad para legitimar su verdadera finalidad, esto es, regular de una manera eficaz los flujos migratorios internacionales, mediante la instauración de un nuevo régimen global de vigilancia fronteriza (Düvell, 2003, apud Doménech, 2013, p. 2). Conforme subraya Stang (2016, p. 10), comparten el mismo objetivo que las políticas más abiertamente restrictivas, ya que siguen valiéndose del empleo de dispositivos de seguridad, adaptando igualmente las legislaciones migratorias estatales a sus exigencias, mediante su reforma o promoviendo la implementación de programas de regularización de migrantes irregulares.

Según Magliano y Clavijo (2011, p. 151), la consecuencia ha sido que solo aquellos desplazamientos realizados de manera regular y ordenada, son considerados como un beneficio para el desarrollo de los países de origen y destino. Mientras que aquellos que tengan carácter irregular y desordenado, son presentados como un proble- 
ma de seguridad y una amenaza, asociándolas a actividades ilícitas vinculadas al narcotráfico, el terrorismo internacional o a la trata de personas. No hay que olvidar que las personas migrantes y refugiadas suscitan que el Estado adopte una posición ambivalente, al pretender proteger los derechos humanos al mismo tiempo que su soberanía. Un aspecto que se agudiza en la gestión de la migración indocumentada, porque el conflicto se produce entre la autoridad estatal de control de entrada y la obligación de proteger a aquellos que se encuentren dentro de su territorio (Sassen, 2001).

Todo ello parece confirmar el planteamiento sugerido anteriormente, esto es, que la lógica de la soberanía está ligada inevitablemente a la lógica de la gobernabilidad neoliberal. Entonces, lo que se pretende mediante las políticas de control de la movilidad en un contexto de capitalismo global, es esencialmente ejercer la persuasión, pero sin coerción, mediante el cálculo y gestión de riesgos basados en criterios racionales o "patrones neutrales" (Mezzadra, 2012 , p. 9). Promovidas actualmente por los organismos internacionales supranacionales, como la Organización Internacional para las Migraciones (en adelante OIM) y Naciones Unidas (NN.UU), estas políticas incluyen medidas restrictivas, coercitivas y punitivas, al mismo tiempo que proclaman la defensa de los derechos humanos. $\mathrm{Su}$ intención es que se haga efectiva la idea de una migración ordenada, promoviendo la legalidad de los flujos migratorios.

Así, se justifican la aplicación de medidas selectivas de visado, el rechazo en frontera, el uso de la biometría en los controles de entrada y permanencia, la detención en centros de internamiento de extranjeros y las deportaciones o expulsiones. Además, a través de tales medidas, se facilita la clasificación de las personas que migran en "deseables" e "indeseables", dependiendo de la naturaleza de los desplazamientos, esto es, ordenados/desordenados, voluntarios/ forzosos y reducidos/masivos. Por consiguiente, los tradicionales criterios de elegibilidad raciales o étnico-nacionales propios de las sociedades occidentales de finales del siglo XIX y principios del siglo XX, han quedado relegados a un segundo plano (Gabbacia, 1999, apud López Sala, 2005a, p. 33; Doménech, 2013, p. 7). 
En 2015, el Consejo de la OIM adoptó el Marco de Gobernanza sobre la Migración, estableciendo aquellos elementos fundamentales para facilitar la migración y la movilidad de manera ordenada, segura, regular y responsable. El objetivo era respaldar a los gobiernos en la planificación y gestión de la migración a escala nacional, poniendo especial énfasis en la movilidad del capital humano (GRFDT, 2016, p. 3). Asimismo, se resaltó la dificultad de los Estados para enfrentar como asuntos domésticos los desafíos y oportunidades que caracterizan a la migración internacional. Tal y como indica la OIM (2015):

Vivimos en una era de movilidad sin precedentes en la que se hace patente la necesidad de facilitar la migración y el movimiento de personas de manera ordenada, segura, regular y responsable. Ahora bien, para conseguir los beneficios y aprovechar el pleno potencial de la migración es preciso contar con enfoques sobre la migración y la movilidad planificados, bien encauzados y debidamente gestionados. No obstante, la migración es una esfera de acción compleja y vasta, que no está consignada en una convención o marco único de gobernanza de la migración que proponga un enfoque coherente, amplio y equilibrado y que sea, además, práctico, concreto y conciso (OIM, 2015, p. 1).

Para cumplir con estos objetivos, la Asamblea General de la Organización de Naciones Unidas adoptó ese mismo año la Agenda 2030, a través de la cual se exhortaba a la comunidad internacional a cooperar en la gestión migratoria, bajo el compromiso del pleno respeto de los derechos humanos de las personas migrantes, refugiadas y desplazadas, independientemente de su situación migratoria (GRFDT, 2 de noviembre de 2016, p. 4). Pero a pesar del contexto de globalización y la consecuente reducción de la soberanía estatal, la política migratoria de los Estados nación representa una respuesta nacional a un fenómeno mundial. Y la soberanía sigue siendo el principio que rige en este ámbito (Ceriani, 2007).

Es decir, los Estados continúan ostentando la potestad soberana de determinar los criterios de admisión y expulsión de los no nacionales, de manera que no existe ningún sistema global para regular 
el movimiento de las personas (OACDH 2015, p. 21). A esta circunstancia se le suma la falta de voluntariedad de los poderes públicos para construir un marco jurídico-político mundial en materia migratoria. En cambio, se regulan unilateralmente determinados aspectos de la misma, como las condiciones de entrada y establecimiento, la atribución de derechos sociales y económicos, así como las posibilidades de incorporación a la comunidad política (López-Sala, 2006; GRFDT, 2 de noviembre de 2016).

Por tanto, desde esta perspectiva se está perpetuando un modelo de gestión migratoria que no favorece el establecimiento de relaciones de igualdad entre nacionales (cuya ciudadanía desde el punto de vista jurídico no se cuestiona), frente a los extranjeros que se encuentren en una situación de irregularidad administrativa, promoviendo "uno de los modos más violentos de legitimar la desigualdad y la exclusión de quienes han sido producidos histórica y socialmente como sujetos indeseables" (Doménech, 2013, p. 14).

\section{CONCEPTO DE SEGURIDAD Y "SECURITIZACIÓN".}

La seguridad es una noción controvertida, porque no hay una definición neutral posible (Smith, 2005, p. 27, apud Diskaya, 1 de febrero de 2013). En la versión castellana de la Real Academia de la Lengua Española, se hace referencia a la misma, como "cualidad de seguro", es decir, algo exento de riesgo, que no falla u ofrece confianza. En su acepción inglesa, el Diccionario Oxford abreviado la describe como "la condición de ser protegido o de no ser expuesto a un peligro"; o como "algo que asegura una protección, salvaguardia o defensa" (Bauman, 30 de diciembre de 2015). Sin embargo, el término "securitización", no está recogido en los diccionarios, al tratarse de un neologismo incorporado de manera reciente al vocabulario mediático y político. Extraído del sistema bancario para ser adaptado y transferido al ámbito de las Relaciones Internacionales (Wæver 1995; Balzacq 2005, p.178; Balzacq, 2009 apud Balzacq, Basara, Bigo, Guittet y Olsson, 2010, p. 2), sirve para interpretar y explicar la reclasificación de algo como una instancia de "inseguridad"; o su transmisión inmediata 
al ámbito, jurisdicción y supervisión de las fuerzas u órganos de seguridad (Bauman, 30 de diciembre de 2015; Bauman, 2016).

Para Bourbeau (2011), la securitización es el proceso de integración discursiva e institucional de un problema dentro de los marcos de seguridad, que enfatiza la actuación policial, el control y la defensa (Bourbeau, 2011, apud Bourbeau, 2015, p. 2). Señala Ariza (2014) que el origen del concepto hay que situarlo justo cuando finalizó la Guerra Fría, momento en el cual existía un gran debate sobre los problemas de seguridad que atenazaban al nuevo orden mundial instaurado tras el bipolarismo. Como resultado de ello, en 1983, Buzan formuló la Teoría de los Complejos de Seguridad (Sisco y Chacón, 2004, p. 134), por la cual ampliaba ésta a cinco grandes sectores: militar, político, económico, social y del medio ambiente, reduciendo la atención puesta en el Estado (Buzan et al., 1998, apud Bourbeau, 2006 pp. 7-8). La seguridad para Buzan (1991) es una cuestión de supervivencia, y la define como la forma que tienen los Estados o las sociedades de librarse de la amenazas, para mantener su independencia e integración funcional, frente a las fuerzas de cambio reconocidas como hostiles (Buzan, 1991, apud Orozco, 2015, p. 148).

Posteriormente, en 1995, el investigador de la Escuela de Copenhague de Estudios Críticos de Seguridad, Ole Waever, acuñó la palabra "securitización" (securitization), como una reacción a las corrientes tradicionalistas sobre estudios de seguridad, esto es, a las teorías realistas y neorrealistas de las Relaciones Internacionales. A través de ella, explicaba el proceso de construcción social por el que un sector ordinario de la política es llevado al ámbito de la seguridad, mediante una retórica del peligro que justifica la adopción de medidas jurídicamente especiales y al margen de los mecanismos ordinarios de decisión política (Waever, 1995, apud Campessi, 2012, p. 5). Es decir, como afirma Campessi (2012), “[...] la securitización es el proceso mediante el cual una cuestión viene transformada en un problema de seguridad, con total independencia de su naturaleza objetiva, o de la relevancia específica de la supuesta amenaza" (Campesi, 2012, p. 5).

De acuerdo con el paradigma realista y neorrealista, la idea de "amenazas" se circunscribía únicamente a peligros de tipo militar, 
generalmente entre países (Treviño, 2016, p. 259). En este modelo, la integridad territorial del Estado es considerado como el único objeto referente de la seguridad, por lo que como entidad suprema, ha de proteger la identidad física, política y cultural frente a las amenazas constantes que vienen de fuera de las fronteras estatales, y que están representadas por otros Estados en el contexto de la anarquía. El objetivo central de la política en este campo, será por tanto disponer de todos los medios militares y recursos geoestratégicos necesarios para preservar el interés de la Nación, mediante la acción bélica (Williams, 2004; Orozco, 2005; González-Navas, 2013; Orozco, 2015). Así, el foco de atención se pone en el fenómeno de la guerra, y en las políticas que los Estados adopten para preparar, prevenir o participar en ella. Una circunstancia que les obliga a estar en constante búsqueda de poder y de seguridad, que estará expresada en términos de capacidad militar (Waltz, 1991, p. 212, apud Borbeau, 2006, p. 7).

Pero el problema de estos enfoques, es que los flujos migratorios constituyen una preocupación de menor importancia, siendo subsumidos como asuntos domésticos, en vez de ser considerados como una preocupación de seguridad internacional que de manera general es contemplado en la política mundial, lo cual no permite comprender de manera adecuada la relación migración y seguridad (Borbeau, 2006, p. 7). Por esta razón, se han ido incorporando al debate otras perspectivas teóricas.

En 1998, Weber, junto con Buzan y De Wilde, desarrollaron su propuesta teórica alternativa a través de la "Teoría de la Securitización" (Fuentes, 2014; Verdes-Montenegro, 2015). Basada en el trabajo de C. Schmitt, mediante la misma, se hacía referencia al carácter extraordinario de las políticas que se estaban implementando frente a las amenazas que fueron identificadas como nuevos problemas de seguridad, y entre las cuales, se incluyó también la migración de personas (Tello, 2011; Ariza, 2014; Bourbeau, 2015; Varela, 2015). Varela $(2015$, p. 3) recuerda que esta Escuela en su enunciación se apropió de un modelo espistémico sobre seguridad nacional, propio de las Relaciones Internacionales y de la Criminología, cuya óptica securitaria daría lugar a un nuevo paradigma de gubernamentabili- 
dad de los fenómenos sociales contemporáneos. Desde entonces, tal y como señala Verdes-Montenegro (2015):

[...] el marco teórico de la securitización se ha aplicado a un amplio abanico de cuestiones, desde las migraciones, el terrorismo y los derechos humanos, pasando por la integración europea, la Guerra Global contra el Terror (GGT) o la salud global y el crimen organizado [...] (Verdes-Montenegro, 2015, p. 112).

La lógica de la securitización dentro de esta perspectiva, es calificada por Bourbeau (2015) como “de la excepción”. En base a ésta, un tema se convierte en un problema de seguridad, cuando un fenómeno representa una amenaza existencial para un objeto referente. Consiguientemente, la securitización se dará cuando con el objeto de frenarla, se apliquen medidas de emergencia y acciones que sobrepasen los límites normales de los procesos políticos $(\mathrm{Bu}-$ zan et. al., 1998, pp. 21 y 23).

Su contribución más importante fue que las dinámicas de seguridad no podían ser reducidas únicamente a relaciones político-militares (Orozco, 2015). A diferencia de los estudios tradicionales, el objeto referente de la seguridad no se ciñe exclusivamente al Estado, sino que es un concepto multidimensional, que involucra también a la sociedad y al individuo, por lo que las amenazas afectan a todo el conjunto y no solamente a una parte. De ahí que en algunos supuestos, la prioridad será preservar la integridad del Estado frente a amenazas externas, pero en otros, como en casos de catástrofes humanitarias, habrá que dar prioridad a la seguridad individual. E incluso, se darán situaciones en las que se buscará securitizar la identidad de grupos sociales, cuando estos se vean amenazados (Pérez-Idiart, 2013, p. 1; Orozco, 2015, p. 148).

Para esta corriente de pensamiento, entonces es fundamental señalar con precisión la naturaleza de esas amenazas y su grado de incidencia en el imaginario colectivo de una Nación, de una sociedad o de los individuos, con el objeto de precisar cuándo una concreta cuestión puede ser objeto de securitización o no (Orozco, 2015). A 
tal efecto, su estudio se centrará, por un lado, en el proceso mediante el cual determinados actores securitizadores (habitualmente líderes políticos), muestran ante el público la existencia de supuestos peligros que sirven de pretexto para aplicar medidas de emergencia; $y$, por otro, en los resultados de tal proceso, que se traducen en un incremento de las medidas de vigilancia, o en la asignación de mayores recursos policiales y de armamento (Treviño, 2016, p. 260).

Conviene recordar que el marco de referencia de la óptica securitaria, está influenciada por las Teorías del Análisis del Lenguaje, por lo cual se atribuye a la seguridad una naturaleza "discursiva" que la vincula a la lingüística y a las prácticas que regulan los discursos (Verdes-Montenegro, 2011; Pérez-Idiart, 2013). Basándose en el trabajo de Wittgenstein, Donnelly (2013) destaca además que el objetivo de la securitización es reemplazar el sistema de reglas existente por otro, pero no en un solo acto, sino mediante la aprobación prolongada de diversas normativas, que se irán entrelazando e irán adquiriendo distintos significados a lo largo del tiempo.

Como afirma Waeber (1998), "algo es un problema de seguridad cuando las élites declaran que así sea" (Waeber, 1998, p. 6). En este sentido, los problemas de seguridad son construcciones sociales producto de nuestro conocimiento, pero son proclamados como tales dentro de un proceso discursivo que los enfatiza y prioriza, para incorporarlos a las políticas públicas específicas y excepcionales que se elaboren al efecto (Fuentes, 2014; Ariza, 2014). Dicho de otro modo, es el instrumento empleado por el poder político y los burócratas para encauzar los miedos y ansiedades hacia determinados argumentos (Campessi, 2012, p. 5). De manera que logran direccionar la toma de decisiones en un determinado sentido, legitimando la intervención del Estado o el aumento de sus prerrogativas, con la aceptación colectiva de la comunidad política de que un fenómeno concreto constituye una amenaza (Campessi, 2012; Balzacq, Léonard, y Ruzicka, 2015; Orozco, 2015).

Es de señalar que en este proceso en el que se confiere un estatus intersubjetivo a la amenaza (Balzacq, 2005), los medios de comunicación juegan un papel determinante. Para Martínez-Lirola 
(2015) y Bañón (2002), estos tienen la capacidad de influir en la opinión pública y en la ideología cuando se tratan fenómenos sociales como el de la migración. Igualmente Van Dijk (2009) advierte que existe una relación directa entre el lenguaje y el poder que se ejerce con él, ya que los discursos reproducen la superioridad de las élites blancas sobre los grupos sociales menos favorecidos. Es decir, el lenguaje no es neutro, sino que tiene carácter performativo, un aspecto que se acentúa con el proceso de securitización, a través del empleo de metáforas bélicas, como "asalto", invasión" y "avalancha"; o criminalizadoras, como "ilegalidad" (Verdes-Montenegro, 2015; Fernández-Suárez, 2011). Dicho léxico será empleado para aumentar la inquietud en la población, ya que afecta a aspectos vitales esenciales como el miedo, el deseo de supervivencia o de libertad. Según indica Verdes-Montenegro (2015):

El mero hecho de señalar un determinado asunto y calificarlo como una amenaza, se asocia a una racionalidad específica cargada de poder simbólico que da forma a un posicionamiento en base al binomio amigo/enemigo, en el cual se legitima el uso de los medios necesarios para acabar con esta amenaza - enemiga - de forma urgente ya que pone en riesgo la vida de una o varias personas de una comunidad — amiga. (Verdes-Montenegro, 2015, p 117).

Resumiendo, cuando se habla de la Teoría de la Securitización, se habrán de observar siempre tres fases diferenciadas (Verdes-Montenegro, 2011; Pérez-Idiart, 2013; Fuentes, 2014; Bourbeau, 2015; Verdes-Montenegro, 2015; Balzacq, et. al, 2015). En una primera fase, los poderes deónticos más representativos invocarán la securitización activando una gramática específica de seguridad a través de actos discursivos o "speech acts". Mediante ellos, se presentará un problema como potencial amenaza para la supervivencia de un objeto referente, legitimando en consecuencia la posterior aplicación de políticas y prácticas excepcionales. Pero para que ese acto discursivo tenga éxito, debe darse una segunda fase, que es el "movimiento securitizador", es decir, ha de obtener la aceptación del 
público receptor o "audiencia". Y así, una vez diseñado socialmente el problema, éste se ubicará por encima de la esfera de la política normal (Verdes-Montenegro, 2011, p. 11), dando paso a una tercera fase, en la que se pondrán en marcha una serie de acciones, que transgredirán los procedimientos ordinarios y garantías normativas. Para ello, se asignarán más recursos y se pondrán en práctica operativos militares, se suspenderán libertades civiles o incluso se modificará el régimen político, afectando a derechos, deberes, obligaciones, exenciones y permisos (Balzacq et al., 2015, p. 25).

Por último, la Teoría de la Securitización encuentra entre sus mayores logros la ampliación del concepto de seguridad, por lo cual, ha sido considerada por muchos académicos como una de las herramientas teóricas con mayor repercusión política y normativa en este ámbito (Verdes-Montenegro, 2015, p. 114). Tal y como señala Bourbeau (2006, p. 9), en principio fue una propuesta teórica creativa para entender el vínculo entre la migración y la seguridad, al reconocer la dimensión subjetiva de la migración securitizada. Al mismo tiempo, Treviño (2016) considera que sirvió para entender cómo en algunos países la migración regular e irregular pasó de ser un tema de política ordinaria, a un asunto que legitimaba la implementación de políticas públicas urgentes. Finalmente, enfrentaba con eficacia la idea de que los migrantes son únicamente producto de los límites territoriales (Faist, 2000, apud Bourbeau, 2006 p. 9).

\section{SECURITIZACIÓN DE LA POLÍTICA MIGRATORIA TRAS EL 11 DE SEPTIEMBRE DE 2001 Y LOS ACTUALES ENFOQUES TEÓRICOS.}

El marco interpretativo de la Teoría de Securitización adquirió mayor relevancia tras los acontecimientos del 11 de septiembre de 2001, momento a partir del cual Estados Unidos endureció sus políticas frente a la migración internacional. Desde ese momento, se comenzó a vincular de manera manifiesta el tema migratorio con el terrorismo, advirtiendo del riesgo que éste podía suponer para la seguridad pública y para la seguridad nacional (Isacson y Meyer, 2012, 
apud Treviño, 2016, p. 261). Sostiene Treviño (2016), que tal retórica tuvo consecuencias directas: se crearon nuevas instituciones, se aprobaron normas especiales, y se incrementó el presupuesto junto con el número de agentes para ejercer el control migratorio. Para él, dicha teoría permitió entender que la securitización es un proceso, en el cual intervienen múltiples actores que buscan convencer al público de que la migración es un peligro. De este modo, estos mismos actores pueden diseñar y disponer justificadamente de una serie de acciones y disposiciones, para su contención o vigilancia, aun cuando suponga la violación de la ley, la Constitución, las normas internacionales de protección de los Derechos Humanos o el propio sentido común (Treviño, 2016, p. 261).

Sin embargo, tal enfoque teórico ha sido objeto de numerosas críticas, tanto en el plano conceptual, como en el normativo, epistemológico y contextual, dando paso al nacimiento de otras escuelas igualmente englobadas en la corriente de estudios con enfoques constructivistas de la seguridad (Bourbeau, 2006; Verdes-Montenegro, 2011; Pérez-Idiart, 2013; Verdes-Montenegro, 2015). Entre ellas, se encuentran la Escuela de París, abanderada por Didier Bigo; la Escuela de Aberystwyth (también conocida como Escuela de Gales o Critical Studies Security), cuyos pioneros son Ken Booth y Wyn Jones (Diskaya, 1 de febrero de 2013); o las Escuelas adyacentes de Estudios Críticos de Fronteras, con Vaughan-Williams a la cabeza (González-Navas, 2013).

En el plano conceptual, la crítica más relevante que se le atribuye, es el excesivo énfasis que pone en lo excepcional y en lo discursivo, infravalorando los dispositivos burocráticos y las prácticas de seguridad cotidianas. Precisamente, este planteamiento dio lugar a la línea propia de investigación desarrollada por la Escuela de París, cuya perspectiva de análisis está fundada principalmente en el pensamiento de Pierre Bourdieu y Michel Foucault (Pérez-Idiart, 2013). Siguiendo a Bourdieu, para esta Escuela la seguridad es un "campo" en el que trabajan diversos profesionales, cuya misión no solo consiste en gestionar las amenazas persistentes que ya existen, sino también en identificar otras nuevas (Bigo, 2002, p. 65, apud Diskaya, 2013). Su máximo exponente, Didier Bigo (2002), desarrolló la 
Teoría de la gobernanza transnacional de la migración, a través de la cual incorporó el término de (in)securitización de actores, como el Estado, y centró su preocupación en el control migratorio, conectándolo con el concepto foucaultiano de biopolítica (González-Navas, 2013; Diskaya, 1 de febrero de 2013).

Apoyado además en la idea de "sociedad en riesgo" (Pérez-Idiart, 2013, p. 1), Bigo (2008; 2002) explica cómo la seguridad se define en gran parte mediante las decisiones burocráticas cotidianas, que generan un sentido de inseguridad y malestar. Los flujos migratorios no controlados y la migración irregular, son considerados como una amenaza, la cual es construida a través del intercambio de miedos y creencias entre distintos actores, durante el proceso de creación de una sociedad en peligro. Así que la (in)securitización de la migración, implica que el discurso de los líderes políticos configure un movimiento contrario a determinados grupos de personas, en el cual intervienen agentes de la seguridad, y donde las prácticas administrativas sirven para gestionar precisamente ese miedo o malestar. Pero el problema es que en su actuación, abusan de su legitimidad para luchar contra los terroristas y criminales, extendiéndolo a otros colectivos, como los migrantes (González-Navas, 2013, p. 5). Es decir, en este proceso de (in)securitización, cualquier intento de obtener la máxima seguridad, siempre produce la máxima inseguridad (Bigo, 2008, apud Balzacq et al., 2010, p. 2).

Esta lógica de la securitización, es calificada por Bourbeau (2015) como "de la rutina" (Bourbeau, 2015, p. 3). Esto es debido a que en ella, algunos actos de (in)securitización llevados a cabo por burócratas, medios de comunicación y agentes privados, están tan presentes en su modus operandi, que nunca se discuten y se muestran como una excepción, cuando en realidad son la expresión de la seguridad institucionalizada (Bigo y Tsoukala, 2008, apud Diskaya, 1 de febrero de 2013). Entonces, los actos discursivos no son decisivos, ya que para comprender estas prácticas, habrá de atenderse a los hábitos de trabajo habituales y a las "disposiciones" específicas, antes que a cualquier argumento que los actores puedan emplear para justificar sus actividades (Bigo, 2014). 
No obstante, hay posturas contrarias a este planteamiento, porque consideran que no explica en profundidad cuáles son los distintos niveles de securitización que existen (Bourbeau, 2015). De manera que Balzacq et al. (2010), sugieren que el concepto de securitización sea revisado desde una perspectiva interdisciplinaria, que analice de manera conjunta el riesgo, la violencia y la inseguridad como procesos. Es decir, será necesario adoptar un enfoque sociológico que permita abarcar no solo las prácticas discursivas, sino también las no discursivas.

Con esta finalidad, Balzacq (2005, p. 172, apud Bourbeau, 2015 , p. 1) propuso reformular la hipótesis de la securitización para adecuarlo a los estudios empíricos, tratando de desarrollar una teoría comprensiva. Según él, la securitización es una estrategia pragmática para afrontar el aura de una amenaza sin precedentes, que ha de conectar tres esferas: la del agente securitizador en un contexto determinado, la disposición psicocultural del público, y la parte dispositiva, que reúne prácticas diferentes. Así, estarán justificados los actos, decisiones y la política específica aprobada al efecto para bloquear su desarrollo. Tal y como él indica, la securitización comprende:

[el] conjunto articulado de prácticas mediante el cual los artefactos heurísticos (metáforas, herramientas de políticas, repertorios de imágenes, analogías, estereotipos, emociones, etc.) son movilizados contextualmente por el actor securitizador, que trabaja para incitar al público a construir una red coherente de implicaciones (sentimientos, sensaciones, pensamientos e intuiciones) sobre la vulnerabilidad crítica de un objeto de referencia, que concuerda con las razones del actor securitizador [...] (Balzacq 2011, p. 3, apud Bourbeau, 2015, p. 2).

Por otra parte, en el plano normativo, se le atribuye un carácter etnocéntrico (Bourbeau, 2006), estatocéntrico, elitista y machista, lo cual dificulta que desde esta perspectiva sean exploradas otras definiciones y discursos alternativos de seguridad, o la inclusión de voces silenciadas (Hansen, 2000; Booth, 2007; Wikilson, 2007, Charrett, 2009; apud Verdes-Montenegro, 2011, p. 13; 2015, pp. 120 y 
126). De la misma manera, Both (2007, apud Verdes-Montenegro, 2015, p. 112), le reprocha su carácter militarista, que deja de lado el nexo seguridad-desarrollo.

Para resolver esta última cuestión, los teóricos de la Escuela de Aberystwyth, cuyos estudios están ligados a investigaciones sobre la paz, proponen una alternativa a la Teoría de la Securitización, a través de la Teoría Crítica de la Seguridad y la Emancipación. De raíces marxistas y destacada por su carácter radical, a través de ella, pretenden lograr la transformación social mediante la exploración e interpretación de las barreras, así como de las posibilidades de la emancipación humana (Diskaya, 2013; Pérez-Idiart, 2013; Balzacq, et al., 2015). Para Both y Jones, la comprensión realista de la seguridad como "poder" y "orden" nunca puede llevar a una "verdadera" seguridad. Dicho de otro modo, el Estado soberano no es su principal proveedor, sino que es el causante de la inseguridad. Es por ello que este término ha de ser reconceptualizado, centrándose en la relación que existe entre los seres humanos y no sólo entre las instituciones (Pérez-Idiart, 2013, p. 2). Según Both (1991, p. 319, apud Diskaya, 1 de febrero de 2013), únicamente se alcanzará la verdadera seguridad a través de la emancipación por parte de las personas y colectivos, siempre que no priven a otros de ella. Y justamente serán estos los que adquirirán el verdadero protagonismo, al ejercer políticas de resistencia como forma de supervivencia.

Finalmente, las críticas vertidas en el plano epistemológico y contextual, son formuladas por la "segunda generación de teóricos de la securitización” (Verdes-Montenegro, 2015, p. 119), quienes destacan la vaguedad de términos y conceptos clave, como "audiencia”, además del exceso de abstracción y subjetivismo en su relación con los problemas reales (Pérez-Idiart, 2013, p. 6).

En total, como se ha podido comprobar, los elementos de la Escuela de Copenhague y la Escuela de París, así como de la Escuela de Aberystwyth, tienen carácter complementario (Diskaya, 1 de febrero de 2013). Este fue uno de los motivos que llevó a algunos de sus miembros a suscribir en 2006 un manifiesto colectivo que recogía y agrupaba los diferentes enfoques críticos de seguridad en 
Europa, conocido como el Manifiesto C.A.S.E. Collective (Colectivo "Critical Approaches to Security in Europe"). Dicho colectivo tenía por objeto evaluar y discutir la evolución de sus propias premisas teóricas, así como de sus repercusiones políticas, especialmente en lo que se refiere al estudio de cuestiones como el "estado de excepción" (C.A.S.E. Collective, 2006; González-Navas, 2013). En su manifiesto, propusieron adoptar una visión multidisciplinar que englobara las materias de seguridad, libertad, migración y desarrollo (Balzacq et al., 2010, p. 1), ya que desde esta perspectiva es posible "re-politizar la seguridad" (Tabernero, 2013, p. 2), dotándola de contenido ideológico, al entender el proceso de securitización ya sea como un acto del lenguaje o de las prácticas (dependiendo de la posición que se adopte dentro de cada escuela), y no como una simple revisión de los aspectos que caracterizan a una amenaza.

\section{EL PARADIGMA DE LA SEGURIDAD EN LA GESTIÓN MIGRATORIA: LAS "POLÍTICAS DEL MIEDO".}

Como se ha visto hasta ahora, la securitización de las migraciones internacionales ha supuesto la incorporación de la seguridad nacional del Estado como eje central de la política migratoria, supeditando la seguridad humana de las personas migrantes y refugiadas a las exigencias securitarias (Farah-Gebara, 21 junio de 2008; Treviño, 2016). Formulada a partir de la noción de "riesgo" (Abrahamsen, 2005; Ríos-Vargas, 2015, p. 51), los vínculos entre migraciones y seguridad manifiestan la forma en la que un tema se extrae fuera de la política ordinaria, ya sea a través de su enunciación o de la práctica, y se enmarca como una amenaza existencial, que exige la puesta en marcha de medidas extremas (Tabernero, 2013; Andersson, 2014).

Así, se han desarrollado las denominadas "políticas del miedo" (Tello, 2011, p. 196; Abrahamsen, 2005, p. 68), que no solo violarán los derechos fundamentales de migrantes y refugiados, sino que constituyen también la combinación idónea para que afloren los sentimientos contrarios hacia ellos (Villota, 13 de febrero 2017; Fanjul, 2014). Con la pretensión de hacer frente a las amenazas que proceden 
de las regiones próximas, la política migratoria securitizada eleva al rango de "emergencia" la movilidad humana, asociando a aquellas personas que provienen más allá de las fronteras occidentales, con fuentes del crimen organizado y del terrorismo internacional. De esta manera, el orden político puede ser suspendido con la aceptación de la opinión pública, dando paso a un "militarismo excepcional" (Bordonado, 2016; Mabee y Srdjan, 2017, p. 2), que se manifestará en el régimen de control fronterizo, mediante el alineamiento de la política de seguridad y defensa nacional con la política exterior.

Es decir, la movilidad humana ya no es solo para los gobiernos un fenómeno económico, demográfico o laboral (Varela, 2015), sino que es reubicada en la esfera del "riesgo real, latente o probable" (López-Sala, 2006; Ríos-Vargas, 2015, p. 51), favoreciendo el surgimiento de posturas hostiles hacia ella (Arango 2011, p. 54, apud Ríos-Vargas, 2015, p. 51). Asimismo, la necesidad de ejercer el control sobre los desplazamientos de personas, ha dado paso a una política de gestión que requiere una mejor tecnología, e incorpora mecanismos preventivos de contención de carácter policial y administrativo (Ariza, 2014, p. 31; Fernández, 2008 y Naranjo, 2014, apud Ríos-Vargas, 2015, p. 51).

La ampliación de la noción de seguridad nacional como pilar de la soberanía estatal (diversificada en las funciones policiales de mantenimiento del orden público), también ha implicado la gradual ampliación de su universo semántico, al incorporar otros modelos securitarios (Campesi, 2012, p. 6; Varela, 2015; Treviño, 2016). Tomando como referencia el trabajo de Campesi sobre esta materia (2012, pp. 6 y 7), Varela (2015) señala que existen tres posibles vías de análisis o paradigmas del modelo securitario actual, que pueden reproducirse simultáneamente o prevalecer uno sobre el otro en determinadas áreas geográficas.

El primero de ellos corresponde al paradigma clásico de la “tautología del miedo" (Dal Lago, 1999, apud Campesi, 2012, p. 6), que está fundamentado en dos líneas argumentativas. Por un lado, se encuentra la línea que plantea que los índices de criminalidad locales son asociados a criterios étnicos. Consecuentemente, como indica Treviño (2016, p. 283), se extiende la idea de que los migrantes, es- 
pecialmente indocumentados, son un riesgo para el orden público interno. Mientras que, por otro lado, en la segunda línea argumentativa, la migración es vinculada al mismo tiempo a amenazas transnacionales, como el terrorismo internacional y el crimen organizado, que ponen en riesgo la seguridad nacional (Campesi, 2012, p. 7).

El segundo paradigma que propone Campesi (2012), parte del aspecto político-identitario de la lógica securitaria, la cual se centra en mayor medida en las diferencias culturales que en las biológicas. Los migrantes y refugiados son vistos como los "otros" que alteran la estructura social de los territorios donde se establecen, poniendo en peligro la cultura autóctona (Varela, 2015, p. 4). De ahí que en los discursos y disposiciones legales se subraye el aspecto identitario, al predominar la idea de que la migración es una amenaza para la integridad cultural y política de la sociedad (Campesi, 2012, p. 7). El resultado será entonces la materialización de políticas públicas y policiales basadas en criterios raciales, además de la creación de instituciones encaminadas a detener el riesgo que los migrantes representan (Treviño, 2016, p. 283). Por consiguiente, la migración es llevada al campo sancionador del Derecho, configurándose una forma de "racismo diferencialista" (Taguieff, 1986), también denominado racismo "culturalista" o "neoracismo", que genera fronteras internas en las sociedades receptoras de migrantes (Carbonell i París, y Morollón, 2004; Campesi, 2012, p. 7; Varela, 2015, p. 4).

Asociado al anterior, se encuentra finalmente el paradigma tradicional de la migración como amenaza socio-económica (Campesi, 2012, p. 7), desde el que se sugiere que los extranjeros son competidores desleales en el mercado laboral, porque abaratan el costo de la fuerza de trabajo y usan los recursos fiscales del Estado de Bienestar, cada vez más reducido (Varela, 2015, p. 4). En un contexto de crisis económica global y de gran incertidumbre social, este argumento es empleado por algunos partidos políticos de extrema derecha y de corte xenófobo, para canalizar el descontento de las masas populares hacia la inmigración, promoviendo "sentimientos de odio y temor ante los inmigrantes y los solicitantes de asilo" (Huysmans, 2000, p. 769, apud Campesi, 2012, p. 7). Así que acorde con este 
planteamiento ideológico, presionarán para que se pongan en marcha medidas restrictivas como la expulsión y la no aceptación de trabajadores extranjeros, la segregación espacial de estos colectivos o la aplicación de recortes en sus derechos sociales (Comelius, Martin y Hollifield, 1995, apud López-Sala, 2006, p. 78; Carbonell i París, y Morollón, 2004; Varela, 2015, p. 4).

Sostiene Varela (2015) que para llevar a cabo este modelo securitario, se ha configurado desde hace varias décadas un sistema de gobierno basado en el diseño de políticas públicas, que incluyen entre sus propuestas el incremento de dispositivos de vigilancia, propios de un estado de excepción (Varela, 2015, p. 5). Según Bourbeau (2006) y Fuentes (2014), tras los violentos acontecimientos del 11-S (seguidos de los atentados del 11-M de 2004 en Madrid, y del 7-J de 2005 en Londres), la migración constituyó una preocupación de seguridad para casi todos los miembros de la OCDE, por lo cual, ésta fue plasmada en diversos planes y acciones contra el terrorismo islámico. Conviene subrayar que como resultado de los operativos desplegados por la Administración Bush a partir de los ataques a las torres gemelas, no solo se reafirmó la soberanía de los Estados Unidos en la guerra contra el terror, sino que también fue el responsable de la generalización de la excepción permanente a escala global, cuya violencia se manifestaría con la suspensión impune del aspecto normativo del Derecho (Agamben, 2005; Durand-Ponte, 2012, p. 6). Tal y como indica Agamben (2005):

[...] el estado de excepción ha alcanzado hoy su máximo despliegue planetario. El aspecto normativo del derecho puede ser así impunemente obliterado y contradicho por una violencia gubernamental que, ignorando externamente el derecho internacional y produciendo internamente un estado de excepción permanente, pretende sin embargo estar aplicando el derecho (Agamben, 2005, pp. 155 y 156).

Desde entonces, el avance de la tecnología a través del uso de los datos biométricos, adquirió un carácter transcendental, ya que se propagó inmediatamente como forma de "control biopolítico de la población” (Varela, 2015, p. 4). De la misma manera, las políti- 
cas migratorias restrictivas y urgentes de control de flujos, se fueron normalizando en el espacio público estadounidense y europeo, bajo el pretexto de dar mayor protección a las fronteras frente a las nuevas amenazas que representaban el terrorismo internacional, el crimen organizado y la migración irregular (Fuentes, 2014; Ariza, 2014).

Sin embargo, este cambio de corriente en la gubernamentabilidad de las migraciones, se había anticipado unos años antes (Arango, 2011; Fuentes, 2014; Varela, 2015). En Estados Unidos, dio comienzo con la Operación Gatekeeper de 1994 (también conocida como “Operación Guardián” u "Operación Muerte”). Con ella, se fortaleció el muro que separaba los pasos fronterizos de San Diego-Tijuana y El Paso-Ciudad Juárez, mediante dispositivos de alta tecnología, con la intención de crear un cerco disuasorio para desviar las rutas migratorias clandestinas de ciudadanos mexicanos y centroamericanos que trataban de cruzar por la frontera sur.

Mientras que en el ámbito europeo, el nuevo rumbo de la política migratoria fue fijado a mediados de los años ochenta, mediante la experiencia del Grupo de Trevi (Terrorism, Radicalism, Extremism and International Violence), un organismo policial supranacional creado en 1976 por la CE, a fin de contener la actividad violenta de grupos armados y coordinar la vigilancia policial comunitaria (Bunyan, 1993, p. 1). A partir de esa fecha, entre sus estrategias de vigilancia del crimen internacional organizado y del tráfico de drogas, se incluiría también la de frenar la migración, sustentada en el control de las fronteras. En resumen, se estaba vinculando de manera premonitoria los desplazamientos de personas con el terrorismo que opera a gran escala, y con otras actividades delictivas transnacionales (Arango, 2011).

\section{LA GLOBALIZACIÓN DE LOS RIESGOS Y LA TRANSFOR- MACIÓN DEL RÉGIMEN DE CONTROL DE FRONTERAS.}

Según Snyder (2005), todo este proceso ha hecho que las fronteras paradigmáticas del control migratorio en Estados Unidos y Europa, ya no cumplan una función puramente militar o económica, sino esencialmente de control policial. Como consecuencia de ello, se han 
reorganizado las estructuras profesionales en el ámbito de la seguridad, dando paso a la participación de otros agentes. Es decir, se han coordinado los distintos mecanismos de cooperación entre organismos de seguridad "internos" (que incluyen a fiscales, policías o agentes aduaneros), y "externos" (como los servicios de inteligencia militar y el ejército). Tanto es así que la participación de estos últimos en los operativos ejecutados dentro del territorio nacional, ha contribuido a desdibujar las diferencias entre las distintas categorías "delincuente" y “enemigo", hasta su equiparación (Balzacq et al. 2010).

Pero este despliegue policial y militar también ha sido coordinado transnacionalmente, a través de la externalización de las funciones estatales de control de fronteras, entrando a formar parte de la Política Exterior de los Estados (Bigo, 2002; Boswell, 2003b, apud López-Sala, 2005a, p. 30; Varela, 2015). Con el despliegue de misiones en el extranjero que crean corredores de fuerzas, se recupera una vieja práctica de la época colonial, mediante la cual determinados países disponían de una policía militar extranjera para la vigilancia del territorio fronterizo (Balzacq et al. 2010). De manera que la transformación de algunos países en "Estados tapón" (López-Sala, 2006, p. 80), es según González-Navas (2013, p. 6), una de las prácticas de los actores gubernamentales que más ha evidenciado la securitización de las migraciones, ya que implica el desplazamiento de recursos a terceros países para que ejerzan el control migratorio, cuando constituye una competencia exclusivamente estatal.

Esto significa que el nexo entre migraciones y seguridad, también ha generado grandes transformaciones en el régimen de control de fronteras (Campesi, 2012, p. 4; Tabernero, 2013, p. 2). En efecto, éstas representan ahora la tecnología de la seguridad, cuya vigilancia policial se ha visto reforzada mediante la defensa militar, logrando elevar su acción a una cuestión de "alta política" o de seguridad nacional. Es decir, la política del confinamiento ha configurado un formidable dispositivo de control tecnológico que funciona mediante la reducción drástica de los derechos y libertades de los migrantes, pero también a través de un amplio entramado de poderes y competencias administrativas en materia de vigilancia en este campo (Campesi, 2011; Campesi, 2012). 
Es por ello que Jerrems (2012) y González-Navas (2013) sugieren tener en cuenta la propuesta teórica desarrollada por Vaughan-Williams (2009) dentro de los Estudios Críticos de Fronteras, conforme a la cual se muestra cómo la puesta en marcha de una serie de acciones en el campo de la seguridad, han dado lugar a tres tipos de confín: el interno, el perimetral y el externo. Su objeto es actuar como líneas de defensa del Estado nación, de tal manera que en su conjunto, conformarán una "frontera biopolítica generalizada". Es decir, el concepto de frontera del Estado es central para la producción de ciudadanos-sujetos, pero también enmarca las formas en las que comúnmente se conceptualiza el término "seguridad". Y en ella, se producen diversos procesos que conducen a dinámicas excepcionales (González-Navas, 2013, p. 11), como es el refuerzo del discurso antiterrorista, aumentando la represión de determinados derechos, o adoptando leyes anti-terroristas que vulneran estándares de derechos humanos.

Más aún, los nuevos confines tratan de hacer frente a situaciones de peligro en esferas que se consideraban hasta entonces salvaguardadas, pues la globalización ha contribuido a que la percepción de los riesgos que nos atenazan, se haya extendido hasta ampliar el concepto de seguridad (González Navas, 2013, p. 2). Según Beck (2002a; 2002b), los riesgos globales se han desplegado a escala planetaria, atrapando sin salida a todas las personas en un espacio mundial compartido de contingencias e incertidumbres, que difícilmente pueden ser controladas en el nivel del Estado nación. Eso es debido a tres circunstancias: su deslocalización, pues las causas y consecuencias del riesgo no se limitan a una única ubicación geográfica, sino que tendrán una naturaleza omnipresente; su incalculabilidad, cuya previsión dependerá de datos científicos elaborados a partir de premisas hipotéticas; y la imposibilidad de que sus efectos sean compensados (Beck, 2008, pp. 5-6).

Como señala Castan (2014), "[...] la seguridad es una necesidad ontológica para el Estado y, en consecuencia, la identidad del mismo depende de las amenazas, la inseguridad y el conflicto" (Castan, 2014, p. 29). Esto significa que el concepto clásico de la frontera científica, se ha ido transformando con el anhelo de optimizar su 
aspecto militar, hasta la conformación de lo que se han denominado fronteras inteligentes. Diseñadas bajo el marco de las políticas migratorias, estos instrumentos de control incorporan barreras físicas y virtuales para agilizar, facilitar y reforzar los procesos de inspección fronteriza, pero sin entorpecer el libre flujo de capitales (Gabriel, Jiménez y Mc Donald, 2006; Rodier, 2013; Rodríguez-Ortíz, 2015).

González Navas $(2013$, p. 2) añade que los cambios en el panorama internacional, también han provocado que fenómenos tan alejados del esquema tradicional de las amenazas, como es el de las migraciones, se sumen y equiparen ahora a las de carácter ecológico, financiero y las asociadas al terrorismo internacional. Como se ha señalada anteriormente, tras el 11-S, la cuestión de los desplazamientos realizados de manera irregular irrumpió con fuerza en el centro del debate político, junto con el comercio de armas, el tráfico de drogas y el crimen organizado. Desde ese momento, aquellas personas que migraban de manera irregular, quienes ostentaban culturas distintas, o procedían de regiones dominadas por el extremismo y la violencia, comenzaron a ser señaladas como una potencial amenaza para la soberanía y la seguridad del Estado (GCIM, 2005, p. 8).

Rodier (2013) afirma que tras estos acontecimientos, Naciones Unidas aprobó la creación del Comité contra el Terrorismo (Resolución 1.373 del Consejo de Seguridad), que exhortaba a los Estados a "impedir la circulación de terroristas o de grupos terroristas, imponiendo controles eficaces de fronteras y de expedición de documentos de identidad y de viaje" (Rodier, 2013, p. 79). Igualmente, antes de conceder el estatuto de refugiado en los países de entrada, debían comprobar que los solicitantes de asilo no hubieran planificado ni facilitado actos de terrorismo, ni participado en su comisión. Acto seguido, el presidente Bush aprobó la ley antiterrorista USA-Patriot Act, marcando una nueva tendencia en la política migratoria y de vigilancia fronteriza a nivel mundial, ya que la migración fue elevada a cuestión de seguridad nacional, extendiendo sus efectos más allá de las fronteras norteamericanas (López-Sala, 2005; Sassen, 2007).

Según Ramonet (2016), se abrió una etapa en la historia contemporánea que ponía fin al ciclo geopolítico vigente tras la caída 
del muro de Berlín (9 de noviembre de 1989) y la desaparición de la Unión Soviética (25 de diciembre de 1999). Para él, en la que se denominó "guerra justa contra el terrorismo", el terror fue utilizado con fines políticos y se aplicó una justicia de excepción, acompañada de toda clase de medidas "liberticias" que transgredieron las libertades y derechos civiles, especialmente de un determinado colectivo de personas (Ramonet, 2016, pp. 26-27). De esta manera, además de las acciones dirigidas al control fronterizo y a la lucha contra la migración irregular, se incorporaron las relativas a la lucha contra el terrorismo internacional. La consecuencia de tales actuaciones fue el establecimiento de un escenario de securitización y militarización, en el que la lógica de la seguridad se vio ampliada por la política institucional, dotando de gran protagonismo a las fuerzas de seguridad del Estado en la gestión migratoria. Así que se atribuyó un exceso de poder a los cuerpos de seguridad y de inteligencia, legalizando la detención administrativa basada en criterios racistas y xenófobos respecto de aquellas personas que supuestamente estaban vinculadas a organizaciones terroristas (López-Sala, 2005).

Un año después, Naciones Unidas identificó la migración como un hecho de acción prioritaria, y al año siguiente la OIM creó la Comisión Global sobre Migraciones Internacionales. Asimismo, en 2004 la cuestión fue abordada por el Parlamento Europeo, donde se planteó la necesidad de actuar en todos los países mediante el despliegue de acciones conjuntas para enfrentarla y detenerla (López Sala, 2005; Doménech, 2013, p. 4). A partir de entonces, dentro de los grupos de amenazas a la seguridad colectiva, los flujos migratorios no controlados son considerados como tales junto con la delincuencia transnacional organizada, el terrorismo, la extrema pobreza, la represión política, las epidemias, y la degradación del medio ambiente (Morillas, p. 2007, pp. 48-49).

Por otro lado, las fronteras adquirieron nuevos significados políticos, simbólicos y estratégicos (López-Sala, 2006), especialmente en aquellas sociedades tradicionalmente receptoras de migración, ya que su transformación física implicó la redefinición ideológica de sus funciones (Andreas, 2002, apud López-Sala, 2006, p. 
82). Según Rodier (2013), a partir de ese momento, se dio paso a un proceso de cambio de las fronteras, mediante la externalización de los controles migratorios y el desarrollo de una nueva tecnología de vigilancia fronteriza. Durante esta fase, surgieron las fronteras virtuales, basadas en un sistema de visados que seleccionaba la entrada de las personas por razón de su nacionalidad, y que integraba una "lista negra" de países de procedencia, en los cuales se profesaba en su mayor parte la religión musulmana. Además se generalizó el empleo de pasaportes biométricos y se incorporaron dispositivos de vigilancia remota (Rodier, 2013, p. 32).

Sin embargo, para Ibrahim (Ibrahim, 2005, p. 63), el hecho de que la migración irregular fuera considerada un peligro para la seguridad o la identidad nacional, expresaba en realidad la forma más moderna de racismo. Tanto es así que Biswas y Nair (2009) sugieren que no debiera sorprender la reacción de reafirmación del poder soberano tras los atentados, pues en cierto modo, se estaba reproduciendo las formas en las que éste ha delimitado (y sigue delimitando) la vida de los marginados del Sur postcolonial y del Norte global.

Es de señalar que en las sociedades receptoras de migrantes, existe una marcada tendencia a la exclusión estructural de las personas extranjeras (CEPAL, 2006, p. 43). Es por ello que términos como "invasión”, y la aceptación de dos clases de ciudadanía en muchas democracias occidentales, que distingue a los ciudadanos "irregulares" de los "extranjeros residentes", está tradicionalmente asociado a Estados coloniales o a aquellos que pretenden preservar una identidad religiosa, étnica o racial. Lo mismo sucede con las poblaciones de apátridas y refugiados, procedentes de Estados fallidos (Brown, 2015). De igual modo, la identificación de la migración irregular con la delincuencia no hace más que responder a los estereotipos promovidos por la opinión pública en torno a la migración clandestina y el refugio, que han conducido inevitablemente a su estigmatización desde la década de los noventa (López-Sala, 2005a, p. 31).

Por consiguiente, la construcción de los muros y barreras que refuerzan la idea de la "tierra asediada" (Rodier, 2013, p. 61) frente a los "invasores", contribuye a acrecentar el deseo de amurallar del 
sujeto que se encuentra en situación de vulnerabilidad, y los muros se convierten en la pantalla en la que se proyecta la figura antropomorfa del "otro" (del "extranjero peligroso"), como causa de los infortunios nacionales (Brown, 2015). Los controles y el acoso al que son sometidos los migrantes pretenden en realidad establecer un enemigo al que combatir, por lo que la lucha contra la criminalidad, se ha convertido en la coartada perfecta para restringir la libre circulación y para llevar a cabo deportaciones masivas por razones de orden público de personas que son estigmatizadas por el simple hecho de su no ciudadanía (Rodier, 2013).

Aleinikoff (2002, citado en López-sala, 2006), añade además que la integridad simbólica de la frontera, genera una imagen seductora de control estatal. Esta idea es sustentada por Rodier (2013) al afirmar que el control de fronteras cumple una función ideológica para dar respuesta a las supuestas preocupaciones de la opinión pública frente a la amenaza que encarnan las personas migrantes y refugiadas. Así, los discursos de los dirigentes políticos occidentales giran en torno a cómo ejercer un mayor control de las personas "no deseadas" que tratan de entrar por sus fronteras, evidenciando que el riesgo se produce con fines políticos. La inseguridad moldea el actual ejercicio del poder (Bauman, 2016), por lo que el despliegue de espectaculares dispositivos de vigilancia y la proclamación de nuevas medidas, son justificados por los poderes públicos porque sirven para aplacar la inquietud que ellos mismos alientan con su discurso del miedo, aunque luego no cumplan las promesas de eficacia que éstas aseguran poseer (Bigo, 2002). Y es que "el alcance simbólico de una barrera cuenta más que la propia barrera" (Rodier, 2013, p. 64).

Sassen (2015) mantiene que al redefinirse el espacio de la economía, cada vez más privatizada y corporativizada, provoca un aumento de la desigualdad. Sin embargo, el Estado de bienestar, que basa su legitimidad en la capacidad de proteger a sus ciudadanos contra los peligros, ya no puede dar respuesta a las demandas exigidas por la sociedad, ni es capaz de proporcionar las condiciones básicas de convivencia y seguridad (Beck, 2002b; Bauman 2016). En consecuencia, los riesgos globales actualmente se "democrati- 
zan" afectando de manera inesperada a personas y grupos que hasta entonces habían mantenido unas estables y seguras condiciones de vida (Beck, apud Subirats, 2015). Este hecho ha sido denominado por Mbembe como "el devenir negro del mundo" (Fernado-Savater, 17 de enero de 2016, entrevista con Mbembe), pues para la economía capitalista "hoy todos somos negros en potencia [...] y susceptibles de ser tratados como un objeto". Debido a lo cual, una parte de la población es designada y tratada como superflua, sometiéndola así a riesgos mayores que al resto. Aunque, evidentemente, estas circunstancias están afectando en mayor medida a aquellos que parten de condiciones más frágiles o precarias.

Como indica Sassen (2015, p. 12), nos encontramos ahora en una fase del capitalismo, en la que las avanzadas políticas económicas de austeridad o ambientales, han generado situaciones de desigualdad extrema. A consecuencia de ello, se han generalizado y globalizado nuevas lógicas de expulsión, que amenazan con desplazar a un número creciente de personas en todo el mundo. A través de este proceso, todo lo que dificulte el lucro, es enviado fuera del sistema, constituyendo "una especie de versión económica de la limpieza étnica en que [...] los elementos considerados problemáticos, se resuelven simplemente eliminándolos" (Sassen, 2015, p. 49).

En este sentido, Bauman (2011, p. 12) advierte que la política tiende a colocar en la parte inferior de la distribución social de las riquezas e ingresos a una parte de la población, siendo categorizadas en el imaginario como "clase marginal", no perteneciente a ninguna clase ni a la sociedad. Sus derechos entonces serán fácilmente despojables, pues no forman parte natural e indispensable del organismo social, de tal suerte que la solución es prescindir de ella. Esto es, las expulsiones representan un proceso de selección, que cortan transversalmente las fronteras, y las divisiones del actual sistema de Estados, alejan el foco de la desregularización de las fronteras nacionales, en el que éstas son vistas como el sitio de nuestra transformación actual (Sassen, 2015, pp. 18 y 233).

Por consiguiente, las dinámicas globales de pobreza extrema, los desplazamientos masivos, los desastres naturales y conflic- 
tos armados, han creado niveles nunca vistos de expulsión social, especialmente en el Sur Global, pero ahora también ha comenzado en el Norte Global, aunque a través de acontecimientos diferentes (Sassen, 2015, p. 77). Ahora podrán observarse resonancias sistémicas entre las cuotas de desempleo, la emigración, los desahucios, la pobreza, los suicidios o las crecientes tasas de encarcelamientos de grupos convertidos en minorías de los países ricos del Norte Global, y la presencia de refugiados almacenados en campos formales e informales, así como los desplazados forzosos o los afectados por enfermedades y hambrunas del Sur Global (Sassen, 2015, pp. 13 y 77).

El Estado se legitima entonces mediante la exacerbación del miedo y la necesidad de seguridad, justificando la implementación de medidas controvertidas, que conducen a la renacionalización del discurso político o a la xenofobia (Sassen, 2001, p.17), lo cual explica el resurgimiento en el ámbito europeo y estadounidense de movimientos nacionalistas o proteccionistas y el crecimiento de la extrema derecha xenófoba, que promueven la política del amurallamiento, además del prejuicio contra la población migrante y refugiada (Almazán, 17 de febrero de 2017). Tal y como señala Bauman (2011), en un contexto de crisis económica y social, "la manipulación de la inseguridad" (Bauman, 2011, p. 61) por medio de la designación de culpables, permite al poder consolidar su autoridad cuando es incapaz de dar soluciones a los problemas de la población. $\mathrm{O}$ dicho de otro modo, se usa la vieja táctica conocida como "del chivo expiatorio" (Rodier, 2013). Así, los migrantes y refugiados que pretenden atravesar nuestras fronteras, son representados como una especie de depredadores que ponen en riesgo los valores universales de la sociedad occidental, y con cuya presencia aumentan inevitablemente los niveles de delincuencia, siendo necesario hacerles frente, aun cuando esto implique distorsiones en la legalidad vigente.

El resultado es que a través de la gestión fronteriza en el ámbito europeo y estadounidense, se promueve la generalización del miedo contra este colectivo de personas, justificando así la aplicación de medidas excepcionales y dispositivos de emergencia, que son diseñados para producir una categoría de sospechosos a priori. De manera que 
el continuo reforzamiento de la vigilancia en las vallas, o el establecimiento de mayores barreras legales, aun cuando éstas impliquen la suspensión de derechos o el levantamiento de garantías que protegen a las personas migrantes y refugiadas, serán normalizadas en un escenario de guerra permanente frente a las amenazas externas que encarnan los extranjeros (Rodier, 2013; Mbembe, 2016).

Así pues, la pérdida de soberanía del Estado nación debilitada y atacada por otras fuerzas, se manifestará en la construcción de muros, que operan al margen de la ley y que recuperan el carácter sagrado de las antiguas civilizaciones. Lo político ya no se expresa mediante los poderes soberanos del Estado, pues éste ha dejado de encarnar un poder supremo, debido a que su identidad no se define ahora por un enemigo identificable y unificado. la disminución de la soberanía se verá restablecida con un nacionalismo militarizado, que reafirma las fronteras y su defensa, gracias también al lobby ejercido por la industria de vigilancia de fronteras y su industria anexa de detención y deportación de migrantes (Brown, 2015, p. 107). Y en consecuencia, la excepción como estructura política fundamental, se ha convertido en regla (Mbembe, 2016, p. 22). En los Estados se renueva la sacralización del territorio como "cuerpo" de la Nación, a través de la defensa acérrima de sus fronteras (Cairo, 2001, p. 36), y la vigilancia fronteriza se convierte entonces en una especie de "performance ritual" (Andreas, 2000, p. 148, apud Brown, 2015, p. 92) que proporciona confortantes imágenes de orden. Satisfacen visualmente el deseo de un poder soberano íntegro, sellando el interior y dejando fuera el peligro exterior, como si fueran "templos tardomodernos que alojan el espectro de la soberanía política" (Brown, 2015, p. 133). De manera que los costes y la eficiencia limitada, son entonces irrelevantes ante el deseo de construirlos.

\section{REFLEXIONES FINALES.}

Como se ha podido ver a lo largo de este artículo, la Teoría de la Securitización y los nuevos enfoques teóricos de los Estudios Críticos de Seguridad y su escuela anexa de Estudios Críticos de Fronteras, 
constituyen el marco de referencia que permite comprender el proceso político por el cual se ha producido el nexo entre la migración y la seguridad, debido a la globalización de los riesgos y a la presencia de actores transnacionales que desafían los límites territoriales de los Estados nación. Así pues, estas escuelas han logrado superar los tradicionales enfoques que ciñen la idea de las amenazas únicamente al ámbito militar y a la presencia de conflictos bélicos entre países. La enfatización del control migratorio y de las medidas policiales vinculadas al mismo, pueden ser explicadas entonces desde la perspectiva de la excepcionalidad y las prácticas discursivas, o desde la rutina de las prácticas institucionales, aunque igualmente bajo la comprensión de la realidad fronteriza como espacio securitario.

En un mundo globalizado e interdependiente, para la lógica securitaria las fronteras constituyen la puerta de entrada, pero también de contención, de los señalados como problemas de seguridad "emergentes", entre los que se incluyen los desplazamientos irregulares de personas, junto con el contrabando, el tráfico de sustancias, y el terrorismo internacional, que ponen en peligro la estabilidad del proyecto europeo y estadounidense. En consecuencia, la política migratoria securitizada está ampliamente interconectada con la política de control de fronteras y de los flujos migratorios, adquiriendo una mayor dimensión en el discurso político a escala global.

Si bien es cierto que los Estados han necesitado desde el inicio de sus tiempos de la delimitación del espacio para la vigilancia y el ejercicio de potestad sobre sus dominios, en un contexto de crisis del capitalismo global, la racionalidad neoliberal ha exacerbado esta necesidad, al estimular la intensificación de los controles migratorios. Por consiguiente, ante la ausencia de un régimen mundial que regule el movimiento de las personas, las fronteras sirven al poder soberano para determinar quiénes pueden circular libremente dentro del ámbito territorial de cada país. El resultado es que las políticas de control de la movilidad poseen un marcado carácter ambivalente, pues por un lado, tratarán de promover la selectividad de las migraciones, categorizando a las personas en "deseables" (asociadas al orden y la legalidad), y en "no deseables" (relacionadas con el desor- 
den y la ilegalidad), a las que se les dificultará e impedirá su entrada o permanencia en el territorio nacional, privándoles de los derechos más básicos por razones de orden público o de seguridad nacional.

Mientras que por otro lado, la preocupación creciente por la seguridad, especialmente a partir del 11-S, ha conducido a la militarización paulatina de las fronteras externas de los Estados nación, ya sea mediante el empleo de dispositivos de alta tecnología, o con el despliegue de fuerzas policiales y militares, que ha ido acompañado de la construcción de grandes vallas y muros que incorporan brutales elementos disuasivos. Esta estrategia también se ha fundamentado en la externalización del control migratorio, tanto mediante la suscripción de acuerdos con países de origen, tránsito y destino de la migración irregular, como con el desplazamiento de fronteras avanzadas en determinadas áreas geográficas, que buscan no solo ampliar el espacio de seguridad en la lucha contra el crimen organizado internacional, sino también contener los flujos migratorios irregulares, poniendo freno a las redes dedicadas al tráfico y/o trata de migrantes. Más aún, supeditada a esta lógica securitaria, existe una amalgama de intereses militares y económicos, que ha favorecido el desarrollo de una gran industria de la vigilancia y defensa, de la que han salido beneficiadas las principales empresas del sector de seguridad y de control de fronteras.

Por otro lado, este escenario bélico contra la migración irregular, requiere ser sustentado a través un enrevesado entramado normativo, que legitima y normaliza toda clase de prácticas represivas excepcionales, y amplía las funciones de vigilancia policial en el interior de los países para detectar posibles amenazas, identificando de manera implícita la figura del migrante irregular o del refugiado con el "enemigo" o con el "delincuente", lo cual conduce a su criminalización y deshumanización, de modo que acaban siendo fácilmente despojados de sus derechos humanos.

Puede afirmarse por tanto que el paradigma de la seguridad nacional sigue ocupando un lugar prevalente en la política migratoria actual, frente al discurso humanitario. De este modo, la instrumentalización del miedo en la nueva fase del capitalismo en la que nos hallamos, conlleva la multiplicación de las barreras legales y físicas que 
ponen freno a la movilidad humana, sirviendo a los poderes públicos como medio para demostrar ante la población que los defienden frente a los peligros que traspasan las fronteras, por lo que adquiere carácter secundario su capacidad para frenar las rutas migratorias.

En ese contexto, se puede observar cómo la defensa contra los pueblos migratorios domina la retórica política, hasta tal punto de normalizar prácticas antes consideradas excepcionales, como son las deportaciones masivas de migrantes, las expulsiones colectivas de refugiados o su internamiento en centros de detención para extranjeros, incumpliendo en numerosas ocasiones las obligaciones derivadas de los acuerdos o convenios internacionales de protección que hayan sido ratificados sobre la materia. Es decir, la soberanía de los Estados nación debilitada por la presencia de otros actores transnacionales, se refuerza mediante la respuesta bélica y el recrudecimiento de la hostilidad hacia las personas migrantes y refugiadas.

En definitiva, los políticos estimulan el miedo, mediante la fortificación y multiplicación de los controles migratorios. Esto significa que están abandonando el imprescindible enfoque de los derechos humanos, justo en un momento en el que se hace más necesario, debido a que la movilidad internacional de las personas se ha visto acentuada en todo el mundo, por los efectos destructivos de los conflictos armados, de los desastres naturales, del cambio climático y de la profundización de las desigualdades económicas causadas por la crisis.

\section{REFERENCIAS}

Abrahamsen, R. Blair's Africa: Securitization and the Politics of Fear. Alternatives 30, pp. 55-80, 2005. In: https://goo.gl/Mv0SaV, accedido en 21 sep. 2016.

Almazán, J.A. Los pasos de la renacionalización. La Jornada. (17 de febrero de 2017). In: http://www.jornada.unam.mx/2017/02/17/ opinion/020a2pol, accedido en 20 jun. 2017.

Agamben, G. Estado de Excepción. Homo sacer (II) y (I). Traducción de Flavia Costa e Ivana Costa. Adriana Hidalgo Editora, S.A. Introducción y entrevista de Flavia Costa, 2005. México: Geopolítica del Instituto de Investigaciones Económicas de la UNAM. In: http:// bit.ly/2yfMPUy, accedido en 15 dic. 2016. 
Andersson, R. Illegality, Inc.: Clandestine migration and the business of bordering Europe. Oakland: University of California Press, 2014.

Arango, J. Diez años después del 11-S: la securitización de las migraciones internacionales. Vanguardia Dossier, 11-S El mundo diez años después, no 41, Octubre-Diciembre, pp. 54-59, 2011. In: http://www. pensamientocritico.org/joaara1011.htm, accedido en 1 oct. 2017.

- Las migraciones internacionales en un mundo globalizado: Vanguardia dossier, ISSN 1579-3370, $\mathrm{n}^{\circ} 22$ (Ejemplar dedicado a: Inmigrantes, el continente móvil), pp. 6-15, 2007. Madrid: Grupo de Estudios sobre Migraciones Internacionales de la Universidad (GEMI) In: https://goo.gl/1P4GwQ, accedido en 19 sep. 2017.

. La explicación teórica de las migraciones. Luz y sombra. Migración y Desarrollo, octubre, $\mathrm{n}^{\circ}$ 001. Red Internacional de Migración y Desarrollo. Zacatecas: Latinoamericanistas, 2003.

Ariza, A. La securitización de la migración, una aproximación desde la cooperación migratoria entre Italia y Libia. 2008-2011. 2014. Estudio de caso Presentado como requisito para optar al título de Internacionalista En la Facultad de Relaciones Internacionales Universidad Colegio Mayor de Nuestra Señora del Rosario, Bogotá, 57 p. In: https:/goo.gl/oWvbEL, accedido en 2 oct. 2017.

Balzacq, T. The Three Faces of Securitization: Political, Agency, Audience and Context. European Journal of International Relation, SAGE, pp. 171-201, 2005. In: https://goo.gl/03q3yW, accedido en 23 feb. 2017.

Balzacq, T.; Basara, T.; Bigo, D.; Guittet, E-P.; Olsson, C.. Security Practices. In R. A. Denemark (Ed.), International Studies Encyclopedia Online. pp. 1 - 30, 2010. Nueva Jersey: Blackwell. In: https:/goo.gl/ g6wJYw, accedido en 26 jul. 2017.

Balzacq, T.; Léonard, S; Ruzicka, J. 'Securitization' revisited: Theory and cases. International Relations, pp. 1-38, 2015. In: https://goo.gl/ RgbEkB, accedido en 20 sep. 2016.

Bauman, Z. Extraños llamando a la puerta. Barcelona: Paidós Ibérica. Estado y Sociedad, 2016.

Bauman, Z. Refugiados, inseguridad, magia. Ctxt. Contexto y acción. Diario Público, $\mathrm{n}^{\circ}$ 45, 30 de diciembre de 2015. In: https://goo.gl/ su7Gog, accedido en 15 dic. 2016.

Bauman, Z. Daños colaterales. Desigualdades en la era global. España: Fondo de Cultura Económica (España), 2011.

Bañón, M. Discurso e inmigración. Propuestas para el análisis de un debate social. España: Universidad de Murcia, 2002.

Beck, U. World at Risk: The New Task of Critical Theory. Development and Society, 37(1), pp. 1-21, 2008. In: https:/goo.gl/FUuzD1, accedido 
en 28 ago. 2017.

Beck, U. La sociedad del riesgo. Hacia una nueva modernidad. Barcelona: Paidós Básica, 2002a. In: https:/goo.gl/c2T9JH, accedido en 4 ene. 2017.

El Manifiesto cosmopolita. Introducción, pp. 1-28, 2002b. España: Siglo XXI de España. In: https://goo.gl/TfKFrv, accedido en 4 ene. 2016.

Bigo, D. The (in)securitization practices of the three universes of EU border control: Military/Navy - border guards/police - database analysts. Security Dialogue, Vol. 45(3), pp. 209-225, 2014. In: https://goo.gl/ DFq97x, accedido en 1 dic. 2017.

. Globalized (In)Security: The field and the Ban-Opticon. In D. Bigo, \& A. Tsoukala (Eds.), Terror, Insecurity and Liberty. Illiberal practices of liberal regimes after 9/11, pp. 10 - 48, 2008. Abingdon: Routledge.

. Security and Immigration: Toward a Critique of the Government of Unease. Alternatives, vol. XXVII, 2002, pp. 63-92, 2002. In: https://goo.gl/ryzzUd, accedido en 8 nov. 2016.

Biswas, S., y Nair, S. International relations and states of exception: Margins, peripheries, and excluded bodies. London: Routledge Taylor \& Francis Group, 2009.

Bordonado, J. Nueva Estrategia Europea de Seguridad. Análisis GESI, 13/2016, pp. 1-26, 2016. España: Universidad de Granada. In: http:// www.ugr.es/ gesi/analisis/13-2016.pdf, accedido en 18 sep. 2016.

Bourbeau, P. Securitization. International Encyclopedia of Social \& Behavioral Science, 2nd edition, Elsevier. London: University of Cambridge, 2015. In: https://goo.gl/jmKW3I, accedido en 5 feb. 2017.

. Migration and Security: Securitization theory and its refinement. San Diego: University of British Columbia, 2006. In: https://goo. gl/47Oo2K, accedido en 17 feb. 2017.

Brown, W. Estados Amurallados, soberanía en declive. Versión digital (Epub). Barcelona: Herder, 2015.

Bunyan, T. (1993). Trevi, Europol and the European state. En Statewatching the new Europe. Statewatch, pp. 1-15, 1993. In: http://www. statewatch.org/news/handbook-trevi.pdf, accedido en 17 ene. 2017.

Buzan, B.; Wæver, O.; De Wilde, J. Security: a new framework for analysis. Boulder, Colo.: Lynne Rienner Pub, 1998.

Cairo, H. Territorialidad y fronteras del estado-nación: Las condiciones de la política en un mundo fragmentado. Política y Sociedad, 36, pp. 29-38, 2001. In: http://eprints.ucm.es/39831/1/Territorialidad.PDF, accedido en 10 sep. 2017. 
Campesi, G. Migraciones, seguridad y confines en la teoría social contemporánea. Revista Crítica Penal y Poder, núm. 3, pp.166-186, 2012. In: http://revistes.ub.edu/index.php/CriticaPenalPoder/article/ viewFile/3657/6724, accedido en 25 sep. 2016.

Carbonell i París, F. y Morollón, M. (2004). Racismo diferencialista, racismo culturalista, neoracismo. Wolters Kluwer Legal. Guías Jurídicas. Temáticos CdP, Editorial Praxis, 2004. In https://goo.gl/ xNoyAE, accedido en 10 ene. 2017.

C.A.S.E. Collective. Critical approaches to security in Europe. A network manifesto. Security Dialogue, 37(4) pp. 443-487, 2006.

Castan, J. La Fortaleza Europea: Schengen, Ceuta y Melilla. Colección Tesis Doctorales. Ciencias Sociales. Ceuta: Instituto de Estudios Ceutíes, 2014.

Comisión de Derecho Internacional de Naciones Unidas (CDI). Informe de la Comisión de Derecho Internacional. $66^{\circ}$ periodo de sesiones $(5$ de mayo a 6 de junio y 7 de julio a 8 de agosto de 2014). Capítulo IV. Expulsión de Extranjeros, pp. 11-89, 2014. In: http://legal.un.org/ilc/ reports/2014/spanish/chp4.pdf, accedido en 26 dic. 2017.

Ceriani, P. Los derechos humanos de los migrantes y las contradicciones del principio de soberanía. Estrategias, oportunidades y desafios para la sociedad civil. Forum Migraciones de la FIDH, Lisboa, 21 de abril, pp. 1-5, 2007. In: https://www.fidh.org/IMG/pdf/Ceriani_ resum_es.pdf, accedido en 10 may. 2017.

Comisión Económica para América Latina y el Caribe (CEPAL). América Latina y el Caribe: migración internacional, derechos humanos y desarrollo. Santiago de Chile: Naciones Unidas, 2006. In: https:// goo.gl/59SpDP, accedido en 19 sep. 2017.

Corte Interamericana de Derechos Humanos (CIDH). OC-18/03, Solicitada por los Estados Unidos Mexicanos. Condición Jurídica y Derechos De los Migrantes Indocumentados, 17 de septiembre de 2003. In: http://www.corteidh.or.cr/docs/opiniones/seriea_18_esp.pdf., accedido en 7 oct. 2017.

Diskaya, A. Towards a Critical Securitization Theory: The Copenhagen and Aberystwyth Schools of Security Studies. E-International Relations Students,1 de febrero de 2013. In: https://goo.gl/2fkwpj, accedido en 21 mar. 2017.

Doménech, E. Las migraciones son como el agua: Hacia la instauración de políticas de "control con rostro humano". Polis, Revista Latinoamericana, $\mathrm{n}^{\circ} 35$. Migraciones sur-sur: Paradojas globales y promesas locales, pp. 1-21, 2013. In: https://polis.revues.org/9280, accedido en 7 ago. 2017.

Donnelly, F. Securitization and the Iraq War: The Rules of Engagement in World Politics. (Critical Security Studies). London: Routledge, 2013. 
Durand-Ponte, V.M. Estado de excepción permanente. Conceptos $y$ fenómenos fundamentales de nuestro tiempo. Instituto de Investigaciones Sociales de la UNAM, 2012, pp. 1-13. Recuperado el 30 de enero de 2017 del sitio web: In: http://conceptos.sociales. unam.mx/conceptos_final/491trabajo.pdf, accedido en 30 ene. 2017.

Esteban de la Rosa, G. Principios del Derecho internacional de los Derechos humanos, ordenamiento de la Unión Europea y Migraciones. In Gloria Esteban de la Rosa, Aly Tandian (coords.). Mejora de las condiciones de la emigración de las personas del África Sudsahariana a la Unión Europea, pp. 77-106, 2015. Granada: Ed. Comares (Estudios e informes sobre inmigración).

Fanjul, G. La politica migratoria en Europa. VII Informe sobre Exclusión y Desarrollo Social en España. Documento de Trabajo 8.11. Fundación FOESSA, pp. 1-27, 2014. In: http://bit.ly/2ygzRGb, accedido en 4 ago. 2017.

Farah-Gebara, M. La securitización y los derechos humanos de los migrantes. Radio La Primerísima, 21 de junio de 2008. In: https:// goo.gl/266xUP, accedido en 7 oct. 2017.

Fernando-Savater, A. Achille Mbembe: "Cuando el poder brutaliza el cuerpo, la resistencia asume una forma visceral". Interferencias. Eldiario.es., 17 de junio de 2016. Recuperado el 18 de junio de 2016 del sitio web: In: https://goo.gl/ZMsFBF, accedido en 18 jun. 2016.

Fernández-Suárez, B. Discurso político parlamentario en España sobre el control de fronteras: continuidades y rupturas (2000-2009). In Natalia Ribas Mateos, ed., El Río Bravo Mediterráneo: Las Regiones Fronterizas en la Época de la Globalización, pp. 351-363, 2011. Barcelona: Edicions Bellaterra.

Fuentes, J.M. (2014). Inmigración: Amenaza y riesgo en la Europa Fortaleza. Un estudio de los flujos migratorios en y hacia la Europa Occidentaly de las respuestas políticas para su control (1950-2005). Informe de Seminario de Grado para optar al grado de Licenciado en Historia Seminario de Grado: Migración y Neoliberalismo. In: https:/goo.gl/f7U9ca, accedido en 12 oct. 2017.

Gabriel, Ch; Jiménez, J.; Mc Donald, L. Hacia las fronteras inteligentes norteamericanas : ¿convergencia o divergencia en las políticas de control de fronteras? Foro Internacional., Vol. XLVI, 3 (185), julio-septiembre, pp. 549-579, 2006. In: https://goo.gl/EBNLvM, accedido en 7 sept. 2017.

Global Comision On International Migration (GCIM). Las migraciones en un mundo interdependiente: nuevas orientaciones para actuar. Informe de la Comisión Mundial sobre las Migraciones Internacionales, 2005. In: https://goo.gl/WfZZmQ, accedido en 1 ago. 2017. 
Global Research Forum on Diaspora and Transnationalism (GRFDT). Documento de referencia para la mesa redonda 3.2 del FMMD. Principios, instituciones y procesos para una migración segura, ordenada y regular, pp. 1-11, 2 de noviembre de 2016. In: https:/goo. gl/yaJNC5, accedido en 3 oct. 2017.

González-Navas, A. Estudios críticos de seguridad, migraciones internacionales y ayuda al desarrollo. Comunicación presentada en el XI CONGRESO DE AECPA. La política en tiempos de incertidumbre. GT 6.15 Estudios críticos de seguridad: casos prácticos. Universidad Pablo de Olavide de Sevilla, 18-20 de septiembre de 2013, pp. 1-17, 2013. In: https:/goo.gl/itMi7A, accedido en 2 mar. 2017.

Hernando, E. ¿Flexibilizando el nomos?: globalización y soberanía en la era del terror. Derecho Pucp, Revista de la Facultad de Derecho, $\mathrm{n}^{\circ}$ 61, pp. 147-163, 2008. In: https://dialnet.unirioja.es/descarga/ articulo/5085175.pdf, accedido en 7 feb. 2017.

Ibrahim, M. The Securitization of Migration: A Racial Discourse. International Migration, Vol. 43 Issue 5, pp. 163-187, 2005. In: https://goo.gl/LVuZH, accedido en 2 mar. 2017.

Jerrems, A. Globalización y proliferación de fronteras: una reseña de los estudios críticos de fronteras. Relaciones Internacionales, núm. 21, octubre. GERI - UAM, pp. 173-182, 2012. In: https://revistas.uam. es/rrii/article/view/5154, accedido en 15 may. 2017.

Kamto, M. Segundo informe sobre la expulsión de extranjeros, del Sr. Maurice Kamto, Relator Especial. EXPULSIÓN DE EXTRANJEROS [Tema 8 del programa] DOCUMENTO A/CN.4/573*, pp. 233-269, 2006. In: http://legal.un.org/ilc/documentation/spanish/a_cn4_573. pdf, accedido en 15 may. 2017.

Kamto, M. Informe preliminar sobre la expulsión de extranjeros, del Sr. Maurice Kamto, Relator Especial. EXPULSIÓN DE EXTRANJEROS. [Tema 7 del programa] DOCUMENTO A/CN.4/554, pp. 209-226, 2005. In: http://legal.un.org/ilc/ documentation/spanish/a_cn4_554.pdf, accedido en 15 may. 2017.

López-Sala, A. Pasar la línea. El Estado en la regulación migratoria desde una perspectiva comparada. Revista Internacional de Filosofía Politica, no 27 (julio), pp.71-100, 2006. In: https://goo.gl/KNLofg, accedido en 4 ago. 2017.

López-Sala, A. M. El control de la inmigración: política fronteriza, selección del acceso e inmigración irregular. Arbor: Ciencia, pensamiento y cultura, pp. 27-39, 2005. In: https://goo.gl/nArGzb, accedido en 4 ago. 2017.

Mabee, B., y Srdjan, V. Varieties of Militarism: Towards a Typology. Workshop "Militarism and Security," March 23-24 2017. The School of Global Studies, University of Gothenburg. 
Konstepedemins väg 2b, Göteborg, pp. 1-19, 2017. In: https://osf.io/ sxk64/?action=download, accedido en 3 ene. 2017.

Magliano, M. J. y Clavijo, J. La trata de persona en la agenda política sudamericana sobre migraciones: La securitización del debate migratorio. Análisis político, $\mathrm{n}^{\mathrm{o}} 71$ (enero-abril), pp. $149-$ 163, 2011. In: https://goo.gl/7BEYTu, accedido en 5 ago. 2017.

Martínez-Lirola, M. Representación discursiva de los asaltos a la valla de Melilla por parte de inmigrantes: ejemplos de invisibilidad de los DDHH. Mejora de las condiciones de la emigración de las personas del África Sudsahariana a la Unión Europea. Gloria Esteban de la Rosa, Aly Tandian (coords.). (Estudios e informes sobre inmigración; 4). ISBN 978-84-9045-267-7, pp. 185-200 Granada: Comares, 2015.

Martínez, J. y Stang, M.F. Lógica y paradoja: libre comercio, migración limitada. Memorias del Taller sobre Migración Internacional y Procesos de Integración y Cooperación Regional, nº 45, 2005. Santiago de Chile: Naciones Unidas, CEPAL. In: https:/goo. gl/6VX1Ca, accedido en 7 ago. 2017.

Mbembe, A. Politiques de l'inimitié. Francia: Éditions la découverte, 2016.

Mendiola, I. Regímenes de movilidad y domesticación del espacio. Política y Sociedad, Vol. 49, n 3, pp. 433-452, 2012. In: http://revistas.ucm. es/index.php/POSO/article/viewFile/38549/39564, accedido en 2 jun. 2017.

Mezzadra, S. Capitalismo, migraciones y luchas sociales. La mirada de la autonomía. Nueva Sociedad, ${ }^{\circ}$ 237, pp. 159-178, 2012. In: http:// www20.iadb.org/intal/catalogo/PE/2012/10585.pdf, accedido en 20 oct. 2017.

Oficina del Alto Comisionado para los Derechos Humanos de Naciones Unidas (OHCHR). Migración y derechos humanos. Mejoramiento de la Gobernanza basada en los Derechos Humanos de la Migración Internacional, pp. 1-48, 2015. In: https://goo.gl/ntqoKy, accedido en 14 oct. 2017.

Organización Internacional de las Migraciones (OIM). Marco de Gobernanza sobre la Migración. Elementos esenciales para facilitar la migración y la movilidad de manera ordenada, segura, regular y responsable gracias a políticas migratorias planificadas y bien gestionadas. C/106/40, 2015. In: https://goo.gl/qHyyJw, accedido en 14 oct. 2017.

Orozco, G. A. El aporte de la Escuela de Copenhague a los estudios de seguridad. Revista Fuerzas Armadas y Sociedad, Año 20, n 1, pp. 141-162, 2015. In: http://www.flacsoandes.edu.ec/agora/el-aportede-la-escuela-de-copenhague-los-estudios-de-seguridad, accedido en 1 jul. 2017. 
Orozco, G.A. El concepto de la seguridad en la Teoría de las Relaciones Internacionales. Revista CIDOB d'Afers Internacionals, $\mathrm{n}^{\circ} 72$, pp. 161-180, 2005. En: http://www.raco.cat/index.php/RevistaCIDOB/ article/view/28455, accedido en 2 mar. 2017.

Pereira, A. El tratamiento de las migraciones internacionales dentro del espacio Iberoamericano: de la coyuntura al enfoque de gobernabilidad migratoria. (4 de mayo de 2014). In: https://goo.gl/ tW8wJx, accedido en 22 dic. 2017.

Pérez-Idiart, H. Un aporte sobre los "Security Studies". Seminario de Práctica Pre-Profesional I. UAI- Subsede Bs. As, pp. 1-6, 2013. In: https://goo.gl/VAgnBv, accedido en 2 feb. 2017.

Ríos-Vargas, A.D. Marruecos y México: dos modelos de securitización migratoria en las fronteras de la globalización. CienciaUAT, vol. 10, $\mathrm{n}^{\mathrm{o}} 1$ (julio-diciembre), pp. 47-55, 2015. In: https://goo.gl/4JF3vt, accedido en 2 oct. 2017.

Rodier, C. El negocio de la xenofobia. ¿Para qué sirven los controles migratorios? Madrid: Clave intelectual, 2013.

Rodríguez-Ortíz, R. ¿Qué es la frontera? Conceptualización actual de la frontera. En: Epistemología de la Frontera. Modelos de sociedad $y$ políticas públicas. México: Eón, UTEP, SIPAM, Iniciativa Ciudadana, 2014, pp. 15-37, 22 de febrero de 2015. México: Estudios Fronterizos. In: https://goo.gl/3aXUVB, accedido en 9 may. 2017.

Samir, F. Excepción, decisión y derecho en Carl Schmitt. Argumentos (Méx.) vol.19, nº.52, sep./dic, pp. 125-145, 2006. In: https://goo.gl/ v6hfL6, accedido en 17 sep. 2017.

Sassen, S. Expulsiones. Brutalidad y complejidad en la economía global. Madrid: Katz, 2015.

. La política migratoria. Del control a la regulación. Minerva: Revista del Círculo de Bellas Artes, No. 5, pp. 4-37, 2007. El Otro entre nosotros. In: http://www.revistaminerva.com/articulo. php?id=145, accedido en 20 feb. 2013.

. Los espectros de la globalización. Buenos Aires: Fondo de Cultura Económica, 2003.

- ¿Perdiendo el control?: la soberanía en la era de la globalización. Barcelona: Ed. Bellaterra, 2001.

Sisco, C. y Chacón, O. Barry Buzan y la teoría de los complejos de seguridad. Revista Venezolana de Ciencia Política, pp. 125-146, 2004. In: https://goo.gl/zCE43e, accedido en 5 dic. 2017.

Sorroza, A. La Conferencia Euroafricana de Migración y Desarrollo: más allá del "espíritu de Rabat". Área: Demografía y Población / África Subsahariana / Europa - ARI No 93, 2006. In: http://goo.gl/ sNpCha, accedido en 30 mar. 2015. 
Stang, M. F. De la Doctrina de la Seguridad Nacional a la gobernabilidad migratoria: la idea de seguridad en la normativa migratoria chilena, 1975-2014. In Seguridad y democracia: ¿antinomia irreductible?, Revista Polis, ${ }^{\circ}$ 44, pp. 1-21, 2016. In: https://polis.revues.org/11848, accedido en 14 oct. 2017.

Subirats, J. (3 de enero de 2015). Ulrich Beck, teórico de la sociedad del riesgo. El País. In: https://goo.gl/mtHD1W, accedió en 6 sep. 2017.

Tabernero, C. Seguridad y frontera. La externalización del confín y de la responsabilidad securitizadora. Comunicación destinada a su presentación en el grupo de trabajo 'Estudios Críticos de Seguridad: disputas y propuestas teóricas' del XI Congreso de la AECPA, Sevilla, 19 de septiembre de 2013, pp. 1-14, 2013. In: https://goo.gl/ qh9KFh, accedido en 2 may. 2017.

Taguieff, P. A. Les présuppositions définitionelles d'un indéfinissable: le racisme. Mots, marzo, no. 12, 1986.

Tello, S. Revisando la securitización de la agenda internacional: la normalización de las políticas del pánico. Relaciones Internacionales, núm. 18, pp, 189-200, 2011. In: http://www. relacionesinternacionales.info/ojs/article/view/320.html, accedido en 21 sep. 2016.

Treviño, J. ¿De qué hablamos cuando hablamos de la "securitización” de la migración internacional en México?: una crítica. Foro int., vol.56 no.2, México abr./jun, pp. 253-291, 2016. In: https://goo.gl/3ScE8e, accedido en 14 ene. 2017.

Van Dijk, T.A. Discurso y Poder. Barcelona: Gedisa, Análisis del Discurso, 2009. In: https://goo.gl/c7JqtS, accedido en 22 feb. 2017.

Varela, A. La "securitización" de la gubernamentalidad migratoria mediante la "externalización" de las fronteras estadounidenses a Mesoamérica. Con-temporánea, $\mathrm{n}^{\mathrm{o}}$ 5, diciembre, pp. 1-17, 2015. In: https://goo.gl/3mfCw6, accedido en 23 de sep.2016.

Vargas-Céspedes, J.P. Mesa 1. Las políticas migratorias en Iberoamérica. Las políticas migratorias, ¿qué son?, ¿para dónde van? En Benito, V.J. (Coord.). Seminario Iberoamericano sobre Políticas Migratorias, Cooperación al Desarrollo, Interculturalidad e Integración Social de los Emigrantes Latinoamericanos en España, pp. 53-78, 2010. In: http://goo.gl/ztFC5I, accedido en 19 abr. 2013.

Vaughan-Williams, N. Border politics: the limits of sovereign power. Edinburgh: University Press, 2009. 
Verdes-Montenegro, F.J. Securitización: agendas de investigación abiertas para el estudio de la seguridad. Relaciones Internacionales, Núm. 29, junio 2015 - Septiembre 2015. Grupo de Estudios de Relaciones Internacionales (GERI) - UAM, pp. 111-131, 2015. In: https://goo.gl/ M9sRiC, accedido en 2 sep. 2016.

. La teoría del poder estructural y la securitización: una propuesta teórica para el estudio de las transformaciones del poder y la seguridad. Comunicación presentada en el XI Congreso Español de Ciencia Política y de la Administración, pp. 11-17, 2011. In: http:// www.aecpa.es/uploads/files/modules/congress/11/papers/984.pdf, accedido en 1 jul. 2015.

Villota, C. Migraciones: nuevo eje de la política de cooperación Europea. DisparaMag. 13 de febrero de 2017. In: https://goo.gl/jhNxs5, accedido en 11 nov. 2017.

Waever, O. Securitization and Desecuritization. En Ronnie D. Lipschutz (Ed) On Security. New York, Columbia University Press, 1998. 